\title{
When Meaning Matters: The Temporal Dynamics of Semantic Influences on Visual Attention
}

\author{
Floor de Groot \\ VU University
}

\author{
Falk Huettig \\ Max Planck Institute for Psycholinguistics, Nijmegen, the \\ Netherlands, and Radboud University
}

\author{
Christian N. L. Olivers \\ VU University
}

\begin{abstract}
An important question is, to what extent is visual attention driven by the semantics of individual objects, rather than by their visual appearance? This study investigates the hypothesis that timing is a crucial factor in the occurrence and strength of semantic influences on visual orienting. To assess the dynamics of such influences, the authors presented the target instruction either before or after visual stimulus onset, while eye movements were continuously recorded throughout the search. The results show a substantial but delayed bias in orienting toward semantically related objects compared with visually related objects when target instruction is presented before visual stimulus onset. However, this delay can be completely undone by presenting the visual information before the target instruction (Experiment 1). Moreover, the absence or presence of visual competition does not change the temporal dynamics of the semantic bias (Experiment 2). Visual orienting is thus driven by priority settings that dynamically shift between visual and semantic representations, with each of these types of bias operating largely independently. The findings bridge the divide between the visual attention and the psycholinguistic literature.
\end{abstract}

Keywords: visual attention, semantic memory, psycholinguistics, visual search, eye movements

It is through mechanisms of attention that we select the visual information that is relevant to us. Most models of visual attention assume a strong role for visual features in target selectionfeatures such as color, orientation, and shape (for reviews, see Theeuwes, 2010; Wolfe \& Horowitz, 2004). However, visual properties are not the only type of information available to the cognitive system, and a crucial question is whether visual attention is also sensitive to the semantic properties of visual objects.

The role of semantics on visual attention has been studied in two related paradigms originating from different fields in psychology. One paradigm is the visual search task, in which observers are instructed to look for a predefined target in an array of various distractor objects. Visual search studies using alphanumeric stimuli have reported more efficient search when the target can be conceptually dissociated from the distractors, whereas visual properties are kept the same (Jonides \& Gleitman, 1972; however see

This article was published Online First August 31, 2015.

Floor de Groot, Department of Cognitive Psychology, VU University; Falk Huettig, Max Planck Institute for Psycholinguistics, Nijmegen, the Netherlands, Donders Institute for Brain, Cognition, and Behaviour, Radboud University; Christian N. L. Olivers, Department of Cognitive Psychology, VU University.

This work was supported by NWO (Netherlands Organization for Scientific Research) under Grant 404-10-321.

Correspondence concerning this article should be addressed to Floor de Groot, VU University, Department Cognitive Psychology, Van der Boechorststraat 1, 1081 BT, Amsterdam, the Netherlands. E-mail: f.de .groot@vu.nl
Duncan, 1983; White, 1977, for initial nonreplications). For example, Lupyan (2008) reported faster search for a $B$ among $p$ s (large conceptual difference) than for a $B$ among $b$ s (small conceptual difference). Using pictures, Moores, Laiti, and Chelazzi (2003) showed that the decision that a target is absent can be hindered when the search display contains an object that is semantically related to the target, for example, a helmet when the observer is looking for a motor bike (see also Meyer, Belke, Telling, \& Humphreys, 2007; Telling, Kumar, Meyer, \& Humphreys, 2010). Furthermore, the first eye movement was also directed more often to a semantically related object than to unrelated objects. These findings indicate that conceptual knowledge associated with individual objects can affect visual selection.

Nevertheless, from the visual search literature it is difficult to assess how semantic biases evolve over time. Studies have typically looked either at the end result of the information processing chain (i.e., manual reaction times [RTs]) or at effects that may occur at the very beginning (i.e., the very first eye movement post display onset), but not in between. It is interesting that results from the field of psycholinguistics suggest that whether visual or semantic information is prioritized may change over time and that semantic biases on visual orienting may become more dominant when there is sufficient time to process the visual stimuli. In particular the visual world paradigm is informative here, due to its resemblance to the visual search paradigm (for recent reviews, see Huettig, Olivers, \& Hartsuiker, 2011; Huettig, Rommers, \& Meyer, 2011). In visual world tasks, an array of multiple visual objects is presented first, after which participants hear a particular word. Eye movements are continuously monitored to provide an 
online measure of cognitive processing of the linguistic input. Studies using this paradigm have revealed that objects that share visual, phonological, or semantic properties with the object indicated by the word, strongly affect orienting, but not all with the same time course. For example, Huettig and McQueen (2007) showed that, after observers heard the word, eye movements were first biased toward objects that were phonologically similar and only later toward objects that were visually or semantically similar. This result points to a cascade of activation where hearing a word will first activate a phonological code, followed by the activation of semantic and visual representations (which appeared to occur largely in parallel). Note that according to this scenario, the various representations associated with the visually presented objects are assumed to be all already activated, since the visual display has been presented a good while before the word, allowing for a visual-linguistic match to happen on a phonological level first and only later on a semantic and visual level.

We can use this cascaded activation model of visual-linguistic interactions to make certain predictions about visual and semantic biases in the standard visual search task. In contrast to visual world studies, observers in visual search studies typically hear or see the target before they see the search display. In this case, by the time the search display appears, the target instruction will already have activated all the relevant representations (phonological, semantic, and visual). More relevant now is the reverse cascade that is triggered by the visual stimuli: These will first activate visual representations and only then semantic and potentially phonological codes (Riesenhuber \& Poggio, 1999; Schroeder, Mehta, \& Givre, 1998). The prediction then is that search will first be biased toward objects that match the sought-for information at a visual level and only later at a semantic level-as expressed through more eye fixations. The cascaded activation model thus predicts a different pattern of visual and semantic influences on visual orienting for when the search display is being previewed (as in the visual world paradigm) compared with when it trails the target instruction (as in the visual search paradigm).

Uncovering the dynamics of semantic influences on visual search would be important for theories of attention. So far, some of the most influential models of visual attention do not include the meaning of individual objects as a guiding property for attention or describe the time course of when differential object properties become salient (e.g., Itti \& Koch, 2001; Wolfe, 2007). Such models implicitly assume static representations of saliency. Moreover, in everyday life the relevant environment is often already there before we commence a search, allowing for the activation of much richer representations of the objects present. This allows for semantic effects to play a potentially much larger role than we tend to register in the typical lab setting where we use early measures and relatively brief displays. Comparing different timings of events is therefore likely to be informative.

One study that comes close to the present purpose is the one of Hwang, Wang, and Pomplun (2011), who investigated whether semantic similarity influences scan paths through real-world scenes. They were primarily interested in whether the eyes preferred objects in the scene that were semantically related to each other (e.g., will you look at the fork when you have just fixated a knife?), which was indeed the case. However, in their Experiment 2 they also looked at whether observers preferentially fixate on objects that were semantically related to the object they had to look for (i.e., the target; e.g., will you look at the fork when you are looking for a knife?). Again there was such a bias, which moreover appeared to become stronger with more fixations into the trial. However, there were some limitations with regard to the present goal. First, as the authors pointed out themselves, semantic guidance could also be explained by spatial proximity, as objects that are semantically related are often also found closer to each other in the scene (e.g., a knife and a fork). Contextual guidance is difficult to rule out when using scenes rather than standalone objects. Second, the authors did not control for visual similarity effects as induced by the sought-for target representation (p. 1202). For example, people may look more often at the fork not only because it is semantically related to the knife but also because it is visually similar to it. Although the authors argued, with reason, that such effects were probably small, they could not exclude them, and their design did not allow for a direct comparison between visual and semantic biases. Finally, the Hwang et al. study also included an experiment in which the scene was previewed (their Experiment 1 ), but in that experiment there was no instruction as to which target to look for, and thus no target-induced semantic biases were investigated, nor any changes in the dynamics of cognitive processing this might cause (as this was not the purpose of the experiment).

In this study, we aimed to directly test the hypothesis that timing is a crucial factor in the occurrence and strength of semantic influences on visual orienting. We did this in several ways: First, we continuously measured eye movements during search, rather than confining analyses to only the first fixation. This allowed us to assess whether biases were static (as is implicitly assumed in many visual attention models) or change over time (as visual world studies suggest). Second, we directly compared within the same group of participants the impact that different stimulus timing procedures of the visual search and visual world scenarios have on cognitive cascade of activation, by either presenting the auditory instruction as to what to look for before picture presentation (no preview condition, resembling typical visual search studies) or after picture presentation (preview condition, resembling typical visual world studies). Figure 1 illustrates the differences in procedure. Third, as also illustrated in Figure 1, we presented an array of standalone objects, rather than a scene, which avoids contextual guidance. On the critical trials, we used two types of objects that were related to the (spoken) target: a visual competitor that shared visual features with the target, but was conceptually dissimilar, and a semantic competitor that was conceptually related, while visually dissimilar. By making the semantically related objects match the spoken word only on one dimension, we controlled for visual similarity, and by including both a visual and a semantic competitor we could directly compare visual and semantic contributions to attentional orienting.

Experiment 1 was designed to test the predictions that derive from the cascaded activation model with regard to semantic versus visual biases. We predicted that in the no preview condition (the standard visual search scenario), semantic biases would emerge but substantially later than visual biases, as the latter have a head start in the cascade of visual processing. No such delay was expected in the preview case, as here time allows both types of representation to become active before the target instruction is known. Note that in Experiment 1 the crucial displays always contained both a semantic and a visual competitor. This allowed us 
No Preview Condition
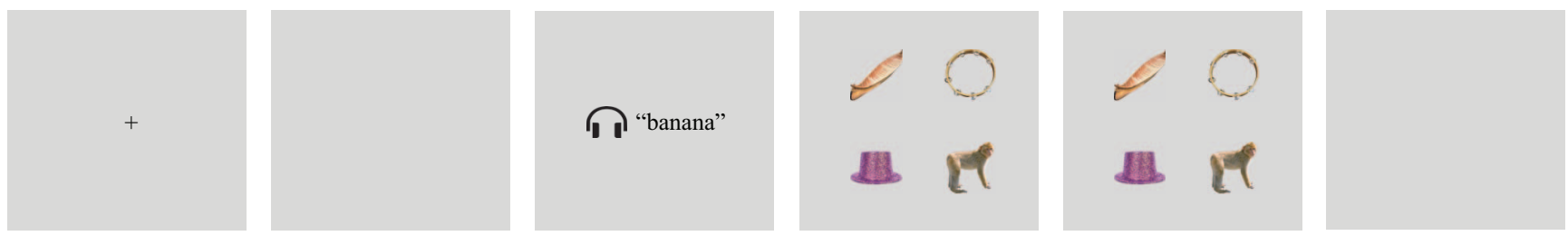

\section{Preview Condition}

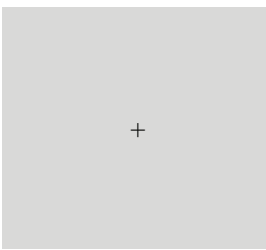

Until Response

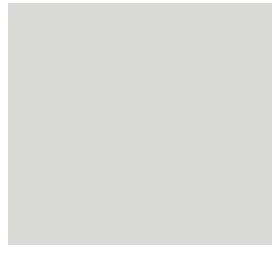

$600 \mathrm{~ms}$

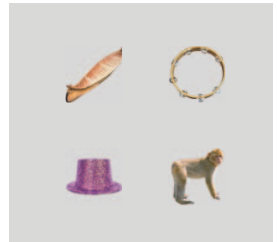

$2000 \mathrm{~ms}$

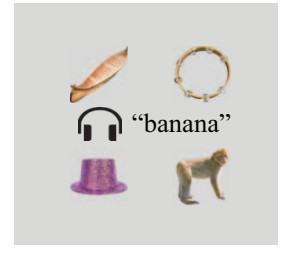

Until Response

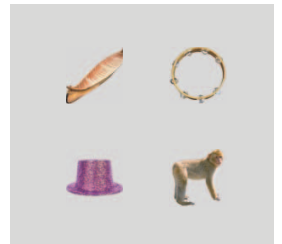

$1000 \mathrm{~ms}$

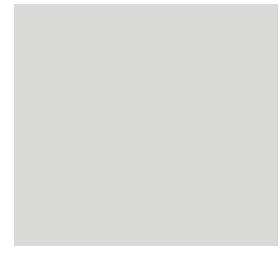

$600 \mathrm{~ms}$

Figure 1. Experimental procedure for a critical (target absent) trial. The word "banana" (originally in Dutch "banaan") was presented through headphones. Here the visual and semantic competitors are the canoe and monkey, respectively. The hat and tambourine are the neutral distractors. See the online article for the color version of this figure.

to directly compare biases against one other, but it could also have given us an incorrect impression of the real timing of the semantic bias. It could be, for example, that visual and semantic representations compete for the available (limited) resources. So when visual representations are activated first, fewer resources are left for the activation of semantic representations than would normally be the case when there was no visual competitor. Thus, the presence of a visual competitor might in itself cause a decrease or a delay in semantic biases. The goal of Experiment 2 therefore was to explore the role of the presence of visual competition, by comparing conditions with a visual competitor to conditions without a visual competitor, and see whether this alters the dynamics of the semantic bias. If not, then this would be evidence for independent visual and semantic influences on visual selection.

\section{Experiment 1}

\section{Method}

Participants. A planned sample of 20 people participated for course credits or money (2 males, age ranged between 18 and 26, with an average age of 20.6). Two participants were replaced because of calibration failure or technical problems during eye movement recording. None of the participants had seen the specific pictures before. All participants reported to be Dutch native speakers with no history of dyslexia (or any other language disorders) or color blindness. The study was positively evaluated by the Ethics Committee of the VU and was conducted in accordance with the declaration of Helsinki.

Stimuli and apparatus. There were 120 target absent trials, each containing four pictures and a word. The set was originally based on a set of 100 trials containing stimuli that were rated and normed on various semantic, linguistic, and visual parameters (de Groot, Koelewijn, Huettig, \& Olivers, 2014), but that was aug- mented with 20 additional trials to increase power. These additional stimuli were normed and rated by the same participants as in de Groot et al. (2014). Every trial contains an object that is semantically but not visually related to the word (semantic competitor), one object that is visually but not semantically related to the word (visual competitor), and two objects that are neither semantically nor visually related to the word (neutral distractors). A semantic relationship between a visual object and the object referred to by the word was defined as sharing something in meaning or function. To the raters it was described as two objects "having something to do with each other (while ignoring visual similarity)". A visual relationship between a visual object and the object referred to by the word was defined as a similarity in visual properties, like shape and color. To raters it was described as "looking similar (while ignoring similarities in meaning)."

All displays had the same gray background (RGB values: 230, 230,230). Table 1 lists the average rating of the strength of the semantic and visual relationships between the words and each competitor type (semantic competitors, visual competitors and the average of the two neutral distractors). Item analysis showed that the semantic competitor was rated as more semantically similar to the target word than the visual competitor and the neutral distractors; whereas the visual competitor was rated as more visually similar to the target word than the semantic competitor and the neutral distractors. Tables 2 and 3 present descriptive and inferential statistics for several visual and linguistic variables. A between-subjects analysis of variance (ANOVA) showed that the three different competitor types did not differ on these, except for the log transformation of word frequency which has recently been proposed by van Heuven, Mandera, Keuleers, and Brysbaert (2014, also referred to as the Zipf-scale and which runs from roughly 1 to 7) Although semantic competitors showed a slightly higher Zipf score, $\log$ (word frequency) fell within the middle of 
Table 1

Similarity Ratings by 61 Dutch Native Speakers for the 120 Target Absent Trials

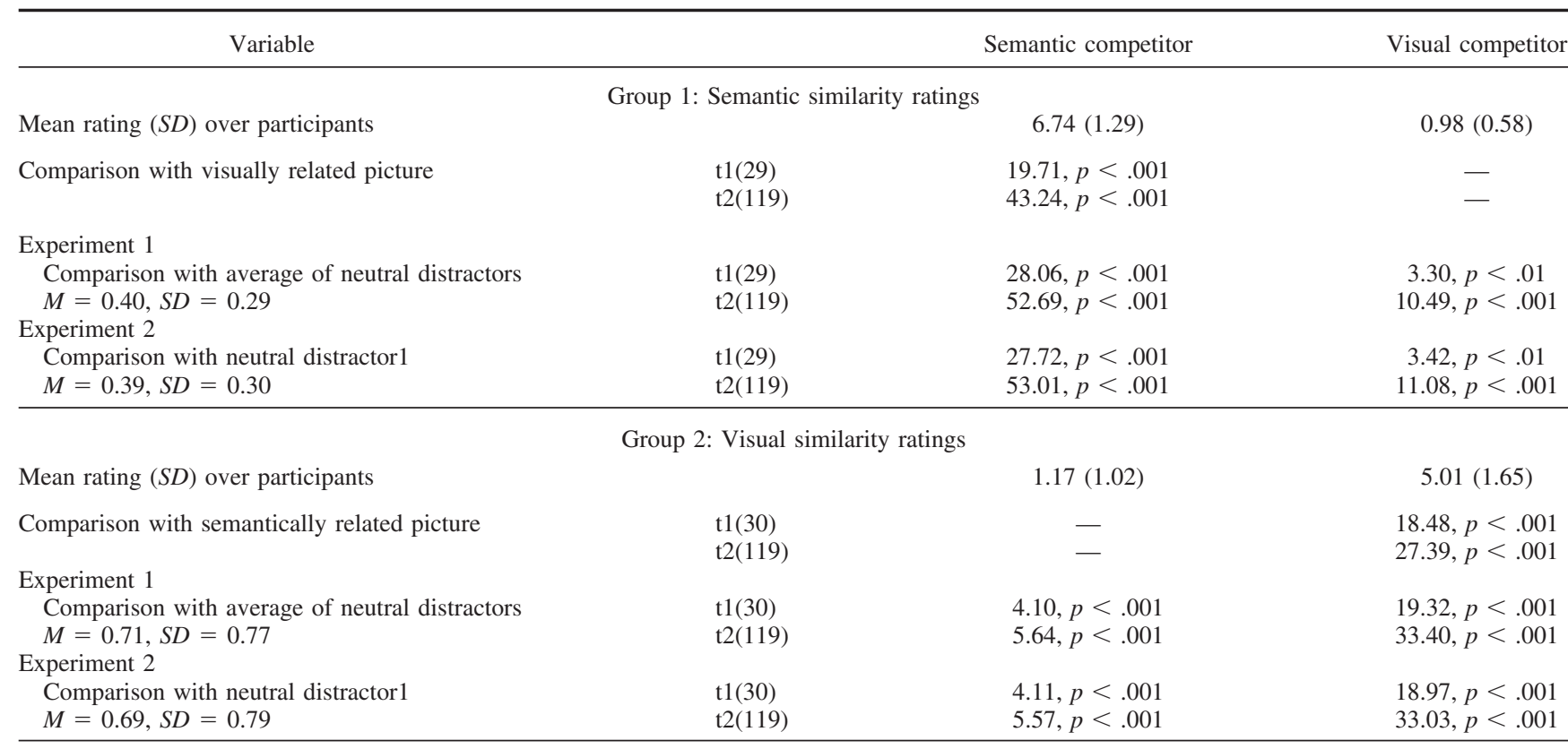

Note. Thirty participants performed semantic similarity ratings, whereas the other 31 performed visual similarity ratings (De Groot et al., 2014). The average rating and $S D$ (in parentheses) are displayed for each rater group and competitor type separately with $t$ tests displaying the comparison between different competitor types. As item-analysis is performed, $\mathrm{t} 1$ reflects the analyses over participants, and $\mathrm{t} 2$ the analyses over items.

the range for all conditions. Furthermore, lenient naming agreement (which includes deflections, synonyms, etc.) showed a trend toward higher naming agreement for the semantic competitors ( $88 \%$ vs. $85 \%$ for the visual competitors and $84 \%$ for the distractors). Both measures suggest that the semantic competitors represent somewhat more stable concepts, which supports their semantic strength.

There were also 120 target present trials in which the spoken word directly referred to an object in the display, while there were no deliberate relationships to other objects. In total there were thus 240 trials in this experiment. Trials were never repeated during the experiment, so each object was only presented once. In total there were 960 unique objects that were either presented as a target, semantic competitor, visual competitor, or as one of the neutral distractors.

The target words for all trials were recorded by the first author and presented through headphones (Sennheiser HD202). A word could be one to four syllables long with on-target absent trials an average duration of $587 \mathrm{~ms}$ (range: 327-926 ms), and on-target present trials $589 \mathrm{~ms}$ (range: $274-950 \mathrm{~ms}$ ). The Appendix lists all target absent trials.

Stimuli were presented in OpenSesame (Mathôt, Schreij, \& Theeuwes, 2012) version 0.27 .3 on a Pentium IV computer $(2.3 \mathrm{GHz})$ with a 21 -in. SVGA monitor (refresh rate of $100 \mathrm{~Hz}$ and

Table 2

Average Scores (SDs) on Several Visual Parameters for Each Competitor Type Separately (Expressed in RGB Grey Level Value Per Pixel)

\begin{tabular}{|c|c|c|c|c|}
\hline Variable & Semantic competitor & Visual competitor & $\begin{array}{l}\text { Neutral distractors taken together } \\
\text { in one group }(n=240)\end{array}$ & Inferential statistics \\
\hline \multicolumn{5}{|l|}{ Luminance } \\
\hline Total & $39(31)$ & $40(33)$ & $35(26)$ & $F(2,477)=1.63, p=.189$ \\
\hline Average & $108(45)$ & $115(43)$ & $106(37)$ & $F(2,477)=2.21, p=.111$ \\
\hline \multicolumn{5}{|l|}{ Contrast within object } \\
\hline Total & $16(11)$ & $16(13)$ & $16(12)$ & $F(2,477)=0.08, p>.250$ \\
\hline Average & $48(17)$ & $49(19)$ & $52(18)$ & $F(2,477)=1.75, p=.175$ \\
\hline Contrast with background ${ }^{\mathrm{a}}$ & $41(25)$ & $35(23)$ & $40(25)$ & $F(2,477)=2.17, p=.115$ \\
\hline Object size & $13,813(7,296)$ & $12,923(8,013)$ & $12,889(7,245)$ & $F(2,477)=0.68, p>.250$ \\
\hline File size of grayscale picture ${ }^{b}$ & $58,546(23,118)$ & $55,211(23,902)$ & $58,307(22,886)$ & $F(2,477)=0.87, p>.250$ \\
\hline
\end{tabular}

Note. Object size is expressed in total number of pixels, and file size is expressed in KB of the PNG compressed image (which is a lossless compression). The last column displays the inferential statistics.

a The RGB values of the background were 230, 230, 230. ${ }^{\mathrm{b}}$ As a correlate of visual complexity, see Donderi and McFadden (2005). 
Table 3

Psycholinguistic Variables for Each Competitor Type Separately

\begin{tabular}{|c|c|c|c|c|}
\hline Variable & Semantic competitor & Visual competitor & $\begin{array}{l}\text { Neutral distractors taken together } \\
\text { in one group }(n=240)\end{array}$ & Inferential statistics \\
\hline \multicolumn{5}{|l|}{ Naming agreement } \\
\hline Dominant name & $76(21)$ & $73(22)$ & $73(23)$ & $F(2,477)=0.94, p>.250$ \\
\hline Intended name & $73(26)$ & $70(27)$ & $71(26)$ & $F(2,477)=0.45, p>.250$ \\
\hline Lenient name & $88(15)$ & $85(19)$ & $84(18)$ & $F(2,477)=2.62, p=.074$ \\
\hline \multicolumn{5}{|l|}{ Word frequency } \\
\hline Per million words & $17(77)$ & $6(15)$ & $10(24)$ & $F(2,425)=1.96, p=.142$ \\
\hline Zipf & $3.47(0.81)$ & $3.17(0.68)$ & $3.25(0.82)$ & $F(2,425)=4.48, p=.012$ \\
\hline
\end{tabular}

Note. Naming agreement is in percentages. Word frequency is expressed as how frequently the name occurs according to SUBTLEX-NL, per million words (Keuleers, Brysbaert, \& New, 2010), plus the log-transformed version of it (referred to as the Zipf measure; Van Heuven et al., 2014). This database did not contain all intended names, and these were treated as missing values explaining the deviating degrees of freedom in the analysis. SDs are in parentheses. The last column displays the inferential statistics.

a resolution of $1024 \times 768$ pixels). The distance from the chinrest to the screen was $56 \mathrm{~cm}$. The right eye of each participant was tracked using an Eyelink 1000 system (Tower model, infrared video-based, SR Research Ltd., Canada) with a temporal and spatial resolution of respectively $1000 \mathrm{~Hz}$ and $0.01^{\circ}$. Pictures were positioned at four fixed positions, one in each quadrant of the display (distance from the midpoint of the picture to center of fixation, $\Delta \mathrm{x}=8.14^{\circ}, \Delta \mathrm{y}=6.07^{\circ}$, and with a diagonal of $10.15^{\circ}$ ). Which picture occupied which position was randomly determined for each trial. Average object size was calculated in two ways: Overall surface size, as expressed in pixels (see Table 2) and through fitting the smallest circle around each object. The radius of this circle was on average 104 pixels $\left(4.15^{\circ} ; S D=9\right.$ pixels, $\left.0.36^{\circ}\right)$, and the distance from central of fixation to the closest edge of the smallest circle around each object was on average $6^{\circ}$.

Design and procedure. The study used a $2 \times 2$ withinsubjects design with condition (no preview vs. preview) and trial type (target absent vs. present trials) as factors. Crucially, embedded in each target absent trial was a semantic competitor, visual competitor, and two unrelated (neutral) distractors. These trials were the ones central to our analyses (but we will also present results for target present trials). The experiment consisted of four blocks of 60 trials each. Condition was blocked, whereas trial type was mixed within blocks (50\% each). At the beginning of each block participants were told through written instructions if the word or the pictures were presented first. They did not receive feedback on their performance. The specific stimulus items were randomized and counterbalanced over participants in a way that per two participants, one participant would have a specific set of items in the no preview condition, whereas the other would have the same set in the preview condition (with the complementary set in the other condition). Possible differences between conditions can therefore not be due to specific items. There were two practice trials presented prior to the experiment.

Each trial started with a drift correction that was triggered by a manual response of the participant when the participant fixated on a cross in the middle of the screen, after which the screen turned blank for $600 \mathrm{~ms}$. In the no preview condition this was followed by an auditory presented word describing the target. Then, 2,000 ms after word onset the search display with the four pictures was presented. Participants had to indicate as fast and accurately as possible if the verbally described object was present or absent in the visual display by pressing the $X$ or $M$ key on the keyboard (counterbalanced across participants). After the button press the pictures remained on the screen for another $1,000 \mathrm{~ms}$ and were then replaced by a blank screen. During this $1,000-\mathrm{ms}$ period eye movement recording continued as we did not know a priori when biases would occur or for how long biases would extend. The new trial started after another $600 \mathrm{~ms}$. In the preview condition the procedure was the same with the exception that the pictures were presented first, and the word was presented 2,000 ms after picture onset.

\section{Results}

Manual responses. Mean RTs for correct responses were entered in a repeated-measures ANOVA with condition (no preview vs. preview) and trial type (target absent vs. present trials) as factors. There were significant main effects of condition and trial type, respectively $F(1,19)=11.98, p=.003, \eta_{\mathrm{p}}^{2}=0.387$, and $F(1,19)=101.50, p<.001, \eta_{\mathrm{p}}^{2}=0.842$, and a trend toward an interaction, $F(1,19)=3.51, p=.08$. Responses were slower in the preview $(M=1,367 \mathrm{~ms}, S D=213)$ than in the no preview condition $(M=1,243 \mathrm{~ms}, S D=241)$, which is probably largely caused by that in the preview condition, RTs were measured from word onset and the word thus still had to unfold and be processed. RTs were also longer on the target absent trials $(M=1,395 \mathrm{~ms}$, $S D=227)$ than on the target present trials $(M=1,202 \mathrm{~ms}, S D=$ 207), which is a standard finding in visual search (probably because on average only half the number of items need inspection on-target present trials). This was mainly the case in the no preview condition, leading to the near-significant interaction.

The same analysis on proportions errors only revealed a main effect for trial type, $F(1,19)=64.20, p<.001, \eta_{\mathrm{p}}^{2}=0.772$, with more errors on-target present trials $(M=0.08, S D=0.03)$ than on-target absent trials $(M=0.03, S D=0.02)$.

Eye-movement data, target absent trials. The target absent trials were the critical trials as they contained the semantic and visual competitors of interest. The most important dependent variable for our purposes was the fixation location as a function of time, for the correctly responded trials. Fixations within squareshaped regions of interest (ROIs) of $200 \times 200$ pixels $\left(7.98^{\circ}\right.$ by $7.98^{\circ}$ ) centered on an object were counted as a fixation. As a starting point for the eye-movement analyses we took the time 
point at which all information was presented to the participant, $\mathrm{t}_{\text {critical }}$. $\mathrm{T}_{\text {critical }}$ was thus the time of picture onset in the no preview condition (as the word was presented before that) and the time of word onset in the preview condition (as the pictures were already present). A period of $2,000 \mathrm{~ms}$ after $\mathrm{t}_{\text {critical }}$ was analyzed and was divided into 20 bins of $100 \mathrm{~ms}$. For each time bin, fixation proportions were computed as the percentage of the time in the bin that a participant fixated on a certain object, as well as withinsubjects 95\% confidence intervals (Cousineau, 2005; Morey, 2008). Where the sphericity assumption was violated (as measured with the Mauchly's sphericity test), the Greenhouse-Geisser corrected values are reported.

With these confidence intervals, Figure 2 allows for a first graphical analysis of the biases in orienting as a function of time. Figure $2 \mathrm{~A}$ and $2 \mathrm{C}$ show the absolute fixation proportions toward the visual competitor, the semantic competitor, and the average of the neutral distractors as a function of time. Figure $2 \mathrm{~B}$ and $2 \mathrm{D}$ show the same data but now as a difference score relative to the average of the neutral distractors. As can be clearly seen from Figure $2 \mathrm{~B}$ and 2D, a significant bias developed toward both the visual and the semantic competitor. Overall, across conditions, the visual bias was stronger than the semantic bias. It is important to note that in the no preview condition the bias started earlier for the visual competitor (at 200- to 300-ms postpicture onset) than for the semantic competitor (at 300 to $400 \mathrm{~ms}$ ). The earliest difference when directly comparing the semantic and visual competitor arose at 300 to $400 \mathrm{~ms}$. Furthermore, extending from 500 to $900 \mathrm{~ms}$, peak activity for the semantic competitor also appeared to be later than for the visual competitor, which showed a clear peak at 400 to $700 \mathrm{~ms}$. Finally, the semantic biases in eye movements were no longer reliable at 1,100 to $1,200 \mathrm{~ms}$, whereas the visual biases were gone a little earlier, by 1,000 to $1,100 \mathrm{~ms}$. In the preview condition the semantic bias emerged earlier (500- to 600-ms postword onset) than the visual bias (600 to $700 \mathrm{~ms})$ and was over sooner $(1,400$ to $1,500 \mathrm{~ms}$ and 1,600 to $1,700 \mathrm{~ms}$, respectively). Here both types of bias appeared to peak around the same time, at 800 to $1,100 \mathrm{~ms}$. The earliest difference between the semantic and visual competitor was around 800 to $900 \mathrm{~ms}$.

To provide a more precise estimate of the time course and the peak strength of the different types of bias, we applied a cubic
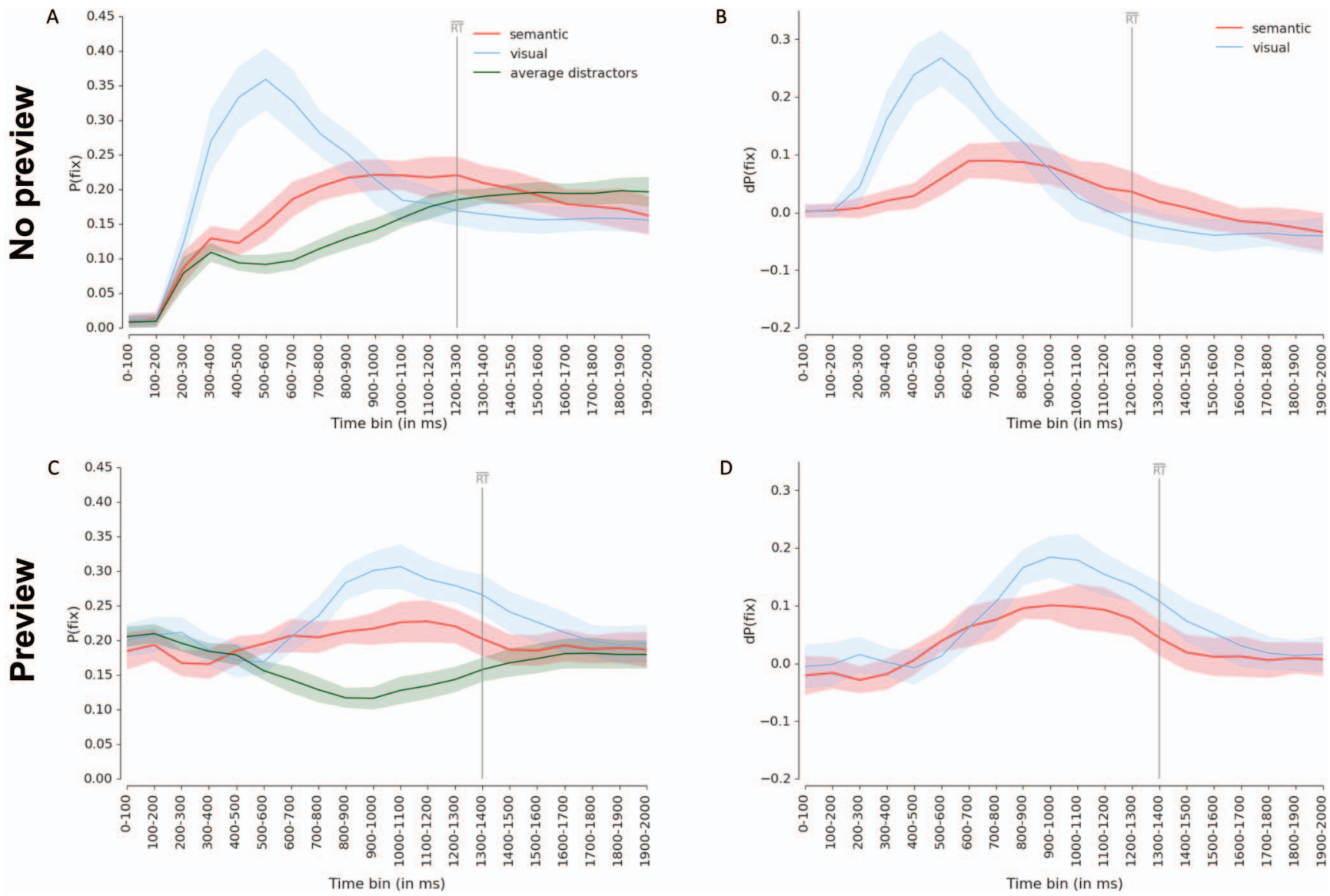

Figure 2. A and $\mathrm{C}$ depict for the target absent trials in Experiment 1 the fixation proportions for each competitor type for each $100 \mathrm{~ms}$ time bin. The grey vertical line is placed at the time bin that includes the average reaction time of that condition. $\mathrm{B}$ and $\mathrm{D}$ depict the difference scores between the semantic competitor or the visual competitor and the average of the neutral distractors. Confidence intervals (95\%, two-tailed) for within-participant designs (Cousineau, 2005; Morey, 2008) are plotted as error bands. See the online article for the color version of this figure. 
spline interpolation method (Matlab R2014a), which fitted for each individual participant a curve through the 20 data points of the semantic and visual difference scores (i.e., the bias relative to the average of the neutral distractors; cf. Figure 2B and 2D). We stress that we chose this method merely on the basis of providing a best description of the data pattern, and we do not attach any theoretical significance to it. For each participant we calculated the time at which the curve peaked, $t_{\text {peak }}$, with the restriction that $t_{\text {peak }}$ had to be later than $150 \mathrm{~ms}$ after display or word onset (as it is unlikely that faster eye movements will be meaningful; moreover, the target present trials also do not suggest any reliable biases before 200 $\mathrm{ms}$ ), and before the average RT of that participant (because we considered any biases after the response less meaningful; furthermore, additional analyses not reported here indicated that there were little to no biases after the response). We then computed the amplitude at $t_{\text {peak }}$, which served as a measure of the strength of the bias. A repeated-measures ANOVA with $t_{\text {peak }}$ as dependent measure and with condition (preview vs. no preview) and competitor type (semantic vs. visual) as factors revealed a significant main effect for condition $F(1,19)=28.19, p<.001, \eta_{\mathrm{p}}^{2}=0.597$, reflecting that biases peaked later in time in the preview than in the no preview condition, respectively $963 \mathrm{~ms}(S D=204)$ and $708 \mathrm{~ms}$ $(S D=243)$. There was also a main effect for competitor type, $F(1$, $19)=10.79, p<.01, \eta_{\mathrm{p}}^{2}=0.362$, as across conditions, semantic biases peaked later than visual biases, respectively $901 \mathrm{~ms}(S D=$ $230)$ and $770 \mathrm{~ms}(S D=269)$. However, and most important for the current purpose, there was a highly significant interaction between condition and competitor type, $F(1,19)=18.51, p<.001, \eta_{\mathrm{p}}^{2}=$ 0.494 . In the no preview condition, the semantic bias peaked later than the visual bias, $t(19)=5.15, p<.001, r=.763$, whereas in the preview condition there was no reliable difference, $t(19)=$ $0.51, p=.619$. Table 4 lists average peak times and amplitudes and their standard deviations.

The same analysis was performed on peak amplitude. There was a main effect of condition, $F(1,19)=5.79, p<.05, \eta_{\mathrm{p}}^{2}=0.233$, with a higher amplitude in the no preview than in the preview condition respectively 0.23 and 0.19 . There was a main effect for competitor type, $F(1,19)=94.52, p<.001, \eta_{\mathrm{p}}^{2}=0.833$, indicating overall stronger biases for the visual than for the semantic competitor, respectively 0.27 and 0.16 . It is important that the interaction was again also significant, $F(1,19)=9.95, p<.01$, $\eta_{\mathrm{p}}^{2}=0.344$. In both the no preview and preview condition the differences in amplitude between visual and semantic biases were significant, respectively $t(19)=7.86, p<.001, r=.875$, and $t(19)=3.83, p<.01, r=.660$, but were larger for the no preview condition (see Table 4). Together, these analyses further confirm what is visible from Figure 2, namely that in the preview condition the semantic and visual biases become more similar, in terms of both time course and strength.

The continuous eye movement measure reported so far reflects, for each bin, the proportion of time spent on an object, which might be driven by proportionally more fixations on these objects, or by longer fixation durations. In turn, increased fixation proportions may stem from an increased number of fixations drawn toward the object from elsewhere, and/or from increased lingering on an object once fixated. To assess which process is responsible for the observed biases, we computed for each competitor type the proportions of attracted fixations (i.e., coming from elsewhere, without consecutive fixations on that particular competitor), the length of the sequence of consecutive fixations on that object, and the average duration (in $\mathrm{ms}$ ) per fixation. If the fixation proportion without the consecutive fixations would be higher for the semantic and visual competitor than for the neutral distractors, this would mean that people orient more frequently toward the competitors. A longer sequence of consecutive fixations for the competitors than for the average of neutral distractors means that people tend to linger longer on the competitors. Note that this latter measure can be distinguished from the average fixation duration which is the time each fixation took on average (another measure of lingering). All three measures were submitted to a repeated-measures ANOVA with condition (preview and no preview) and competitor type (semantic competitor, visual competitor and an average of the two neutral distractors) as factors. Only fixations $150 \mathrm{~ms}$ after display onset (no preview) or word onset (preview) were included.

For attracted fixation proportions (i.e., initial fixations on an object without consecutive fixations), there was an effect of competitor type, $F(1.52,28.93)=54.41, p<.001, \eta_{\mathrm{p}}^{2}=0.741$, but no effect of condition, $F(1,19)=0.07, p=.793$, nor an interaction effect, $F(2,38)=1.28, p=.290$. Follow-up $t$ tests showed that in the no preview condition the visual competitor $(M=0.30, S D=$ $0.04)$ and semantic competitor $(M=0.27, S D=0.02)$ both differed significantly from the average of the neutral distractors $(M=0.22, S D=0.02)$, respectively, $t(19)=5.70, p<.001, r=$ .794 , and $t(19)=7.46, p<.001, r=.863$. In the preview condition the pattern was the same: Attracted fixation proportion was higher for the visual $(M=0.29, S D=0.02)$ and the semantic competitor $(M=0.28, S D=0.03)$ than for the average of neutral distractors $(M=0.22, S D=0.02)$, respectively, $t(19)=7.77, p<$

Table 4

Average and Amplitude (SDs) of $T_{P e a k}$ of the Spline Fitted Function on the Differences Scores for Each Condition and Each Bias in Each Experiment Separately

\begin{tabular}{lcccc}
\hline \multicolumn{1}{c}{ Variable } & $\begin{array}{c}\text { Sematic bias } \\
\mathrm{T}_{\text {peak }}\end{array}$ & Amplitude & $\begin{array}{c}\text { Visual bias } \\
\mathrm{T}_{\text {peak }}\end{array}$ & Amplitude \\
\hline $\begin{array}{l}\text { Experiment 1 } \\
\quad \text { No preview }\end{array}$ & & & & \\
$\quad$ Preview & $852 \mathrm{~ms} \mathrm{(233)}$ & $0.15(0.04)$ & $564 \mathrm{~ms}(152)$ & $0.32(0.09)$ \\
Experiment 2 & $950 \mathrm{~ms}(222)$ & $0.16(0.07)$ & $977 \mathrm{~ms}(188)$ & $0.23(0.08)$ \\
$\quad$ No preview, visual competitor absent & $583 \mathrm{~ms} \mathrm{(160)}$ & $0.22(0.10)$ & - & - \\
$\quad$ No preview, visual competitor present & $682 \mathrm{~ms}(296)$ & $0.21(0.08)$ & $501 \mathrm{~ms}(134)$ & $0.35(0.09)$ \\
$\quad$ Preview, visual competitor absent & $832 \mathrm{~ms}(279)$ & $0.24(0.12)$ & - & - \\
$\quad$ Preview, visual competitor present & $795 \mathrm{~ms}(266)$ & $0.27(0.12)$ & $911 \mathrm{~ms}(241)$ & $0.27(0.12)$ \\
\hline
\end{tabular}


$.001, r=.872$, and $t(19)=6.06, p<.001, r=.812$. We also found effects for the length of the fixation sequence, now for both condition and competitor type, respectively $F(1,19)=21.38, p<$ $.001, \eta_{\mathrm{p}}^{2}=0.530$, and $F(1.33,25.24)=62.84, p<.001, \eta_{\mathrm{p}}^{2}=$ 0.768 . There was no interaction effect, $F(2,38)=1.40, p=.259$. The sequences of consecutive fixations on objects were longer in the preview than in the no preview condition (respectively $M=$ $1.33, S D=0.10$ and $M=1.24, S D=0.07)$. In the no preview condition the sequence was longer for the visual $(M=1.40, S D=$ $0.14)$ and semantic competitor $(M=1.19, S D=0.09)$ than for the average of the neutral distractors $(M=1.12, S D=0.06)$, respectively, $t(19)=10.93, p<.001, r=.929$, and $t(19)=4.08, p<$ $.01, r=.683$. In the preview condition there were also longer sequences of consecutive fixations for the visual $(M=1.45, S D=$ $0.17)$ than for the average neutral distractors $(M=1.23, S D=$ $0.14), t(19)=6.74, p<.001, r=.840$, and a trend for the semantic competitor $(M=1.30, S D=0.11), t(19)=1.98, p=$ .620 .

Finally, for the average fixation duration (in ms per fixation), there was a main effect of condition, $F(1,19)=66.23, p<.001$, $\eta_{\mathrm{p}}^{2}=0.777$, but no main effect of competitor type, $F(2,38)=0.01$, $p=.993$, nor a significant interaction effect, $F(2,38)=0.57, p=$ .571 . Fixations took longer in the preview $(M=305 \mathrm{~ms}, S D=56.46)$ than in the no preview condition $(M=232 \mathrm{~ms}, S D=36.17)$, but there seemed to be no difference between competitors. These analyses thus show that people orient more frequently toward the competitors than toward the distractors (i.e., higher fixation proportion when cumulative fixations are not included) and tend to make more consecutive eye movements on them (i.e., longer sequence length). However, individual fixations on the competitors were not prolonged compared with the neutral distractors as the average duration did not differ.

Eye-movement data, target present trials. For the sake of completeness, we also provide an analysis of the target present trials. Figure 3A shows the absolute fixation proportion toward the target and the average of the three nontargets. From this graph it is clear that there is a large bias toward the target that arises from bin 200 to $300 \mathrm{~ms}$ onward for the no preview condition and from bin 400 to $500 \mathrm{~ms}$ onward for the preview condition. In the no preview condition the bias seems to peak in bin 600 to $900 \mathrm{~ms}$ and in the preview condition between 800 and 1,300 ms. These differences in timing between conditions arose probably because in the preview condition the word took time to unfold. In both conditions the bias toward the target continued until after the response.

Note that a direct comparison of this target bias to any of the visual or semantic biases in the target absent trials is not necessarily meaningful. As the target object and the spoken word match on both a visual and a semantic level, it may be tempting to consider the bias toward the target as a summation of both types of effect. But the word and target object can match on more levels than a semantic and visual one. Notably, a phonological match between the word and the visual object is also likely to contribute to the target bias (Huettig \& McQueen, 2007). In any case the graph shows a clear bias toward the target and, thus, at the very least serves as a sanity check for our analyses.

\section{Experiment 2}

Experiment 1 showed that in the no preview condition the visual bias was earlier in time (and stronger) than the semantic bias, whereas in the preview condition the visual and semantic bias became more similar in terms of both timing and amplitude. The goal of Experiment 2 was to see whether the temporal dynamics of the semantic bias would change without visual competition. It is possible that in the no preview condition, the semantic bias is delayed because the visual bias is so dominant. Alternatively, the time course of the semantic bias could be independent of any visual competition. To investigate this we compared semantic biases for a condition where a visual competitor was present to a condition where it was absent. Like in Experiment 1, we also examined the effect of previewing the visual displays.

\section{Method}

Participants. A planned sample of 24 people participated for course credits or money ( 8 males, age range between 18 and 29, with an average age of 21.33). Two participants were replaced as they scored overall less than $90 \%$ correct. One participant was replaced because of technical failures in data acquisition. The same criteria were used as in Experiment 1.

Stimuli and apparatus. The same trials were used as in Experiment 1 (120 target absent and 120 target present trials), but trials contained now three instead of four visual items. This was because in the visual competitor absent condition, the visual competitor had to be replaced with a neutral distractor, and we had only two independently rated, named, and controlled neutral distractors per trial. On visual competitor present trials the semantic and visual competitor were shown together with one distractor (neutral distractor 1 in the Appendix), while on-target absent trials without the visual competitor the semantic competitor was shown together with two unrelated distractors, neutral distractor 1 and neutral distractor 2 in the Appendix). The set of neutral distractor 1 was thus presented in both conditions and served as the common baseline.

Pictures were presented equidistant to each other, with their midpoint on an imaginary circle around central fixation, with a radius of 175 pixels $\left(7.0^{\circ}\right)$. Pictures were again randomly assigned to each location. For this reason, the ROIs were now circular (radius of 100 pixels, $4.0^{\circ}$, centered on the object), as with square ROIs the distance from central fixation to the ROI would vary with the orientation of the array.

Design and procedure. The study used a $2 \times 2 \times 2$ withinsubjects design with trial type (target absent vs. present trials), condition (no preview vs. preview), and presence of visual competitor (present vs. absent) as factors. The experiment consisted of four blocks of 60 trials each. Condition was blocked, whereas trial type and presence of visual competitor was mixed within blocks (50\% target present trials, $25 \%$ target absent with visual competitor and $25 \%$ target absent trials without a visual competitor). The procedure and timing was the same as Experiment 1, except that stimulus items were now randomized and counterbalanced per eight participants instead of per two. Note that in this experiment too eye recording continued for another $1,000 \mathrm{~ms}$ after response to make the experiments as comparable as possible.

\section{Results}

Manual responses. Mean RTs for correct responses were entered in a repeated-measures ANOVA with condition (no 


\section{Experiment 1}
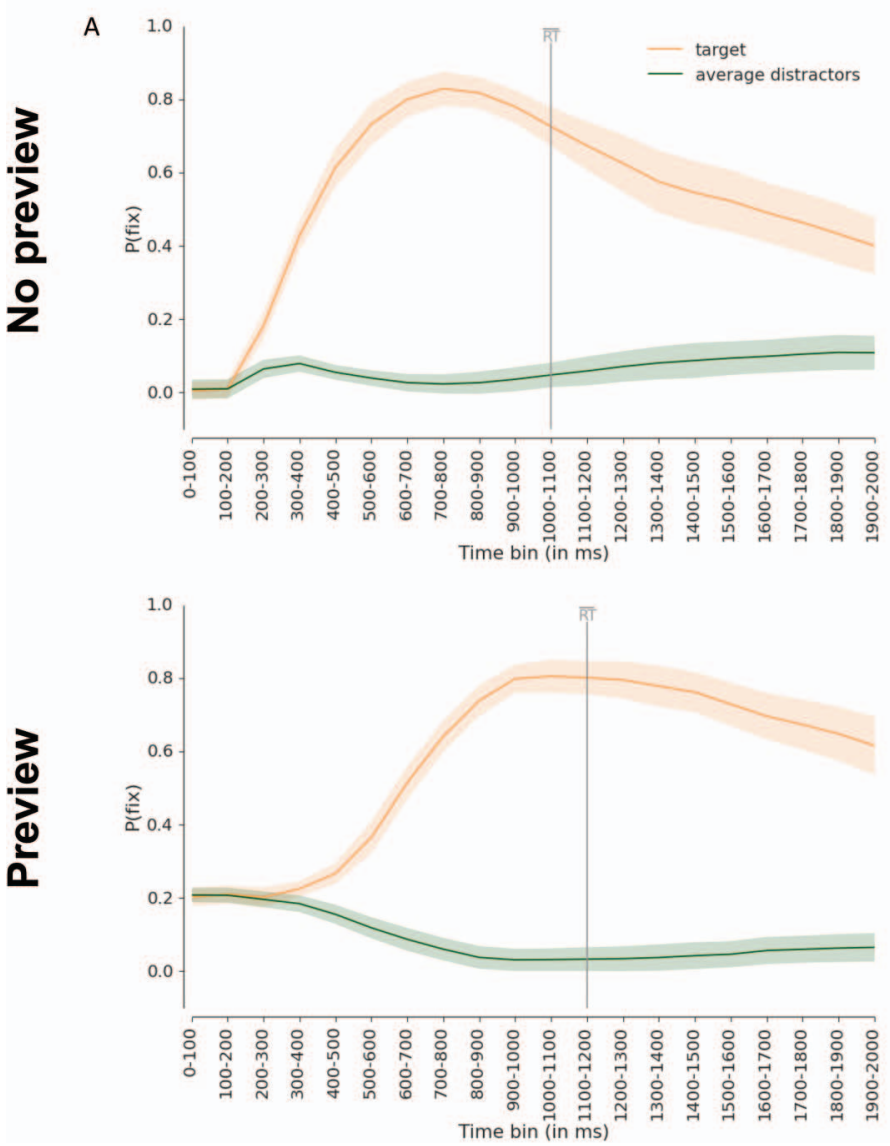

Experiment 2
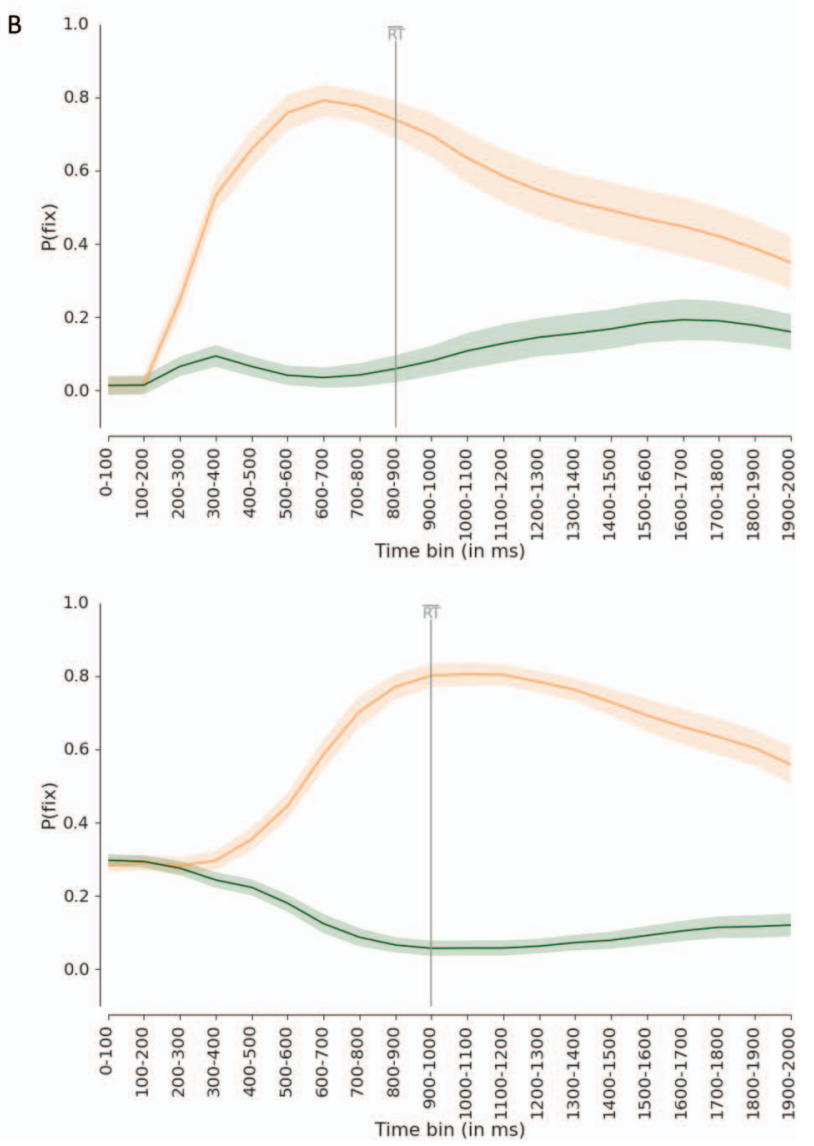

Figure 3. Fixation proportions per time bin for the target present trials of Experiment 1 (A) and Experiment 2 (B). The grey vertical line is placed at the time bin that includes the average reaction time. Confidence intervals (95\%, two-tailed) for within-participant designs (Cousineau, 2005; Morey, 2008) are plotted as error bands. See the online article for the color version of this figure.

preview vs. preview) and trial type (target present vs. target absent with visual competitor vs. target absent without visual competitor trials) as factors. There were significant main effects for condition and trial type, respectively, $F(1,23)=9.25, p<$ $.01, \eta_{\mathrm{p}}^{2}=0.287$, and $F(2,46)=45.47, p<.01, \eta_{\mathrm{p}}^{2}=0.664$. For the interaction effect there was a trend, $F(2,46)=2.68, p=$ .079. As in Experiment 1 RTs were slower in the preview $(M=$ $1,156, S D=163)$ than in the no preview condition $(M=1,055$, $S D=278)$. Participants responded fastest on-target present trials $(M=1,000 \mathrm{~ms}, S D=183)$, followed by trials on which both the target and visual competitor were absent $(M=1,111$ $\mathrm{ms}, S D=209$ ). RTs were slowest on those target absent trials that contained a visual competitor $(M=1,206 \mathrm{~ms}, S D=266)$. These differences between trial types were somewhat more pronounced in the no preview than in the preview condition probably causing the trend to significance in the interaction.

The same analysis on proportions errors revealed only a main effect for trial type, $F(2,46)=26.08, p<.001, \eta_{\mathrm{p}}^{2}=0.531$, with most errors occurring on-target present trials $(M=0.06, S D=$ $0.04)$, target absent trials with a visual competitor $(M=0.04$,
$S D=0.03)$, and least on-target absent trials without a visual competitor $(M=0.02, S D=0.02)$.

Eye-movement data, target absent trials. As in Experiment 1 fixation proportion per 100-ms time bin served as a dependent variable. Figure 4 shows the time-course of the average biases toward different competitors, together with within-subjects $95 \%$ confidence intervals (Cousineau, 2005; Morey, 2008). Figure 4A and $4 \mathrm{D}$ show the absolute fixation proportion over time in the condition with a visual competitor and Figure 4B and 4E for the condition without a visual competitor, for respectively the no preview and the preview condition. Figure $4 \mathrm{C}$ and $4 \mathrm{~F}$ display the absolute fixation proportion of only the semantic biases for the condition with and without the visual competitor in one graph. The difference scores (i.e., bias toward a competitor minus the bias toward neutral distractor 1) are depicted in Figure 5. Again, the 95\% confidence intervals allow for a graphical analysis. As in Experiment 1, there were clear biases toward the visual and semantic competitor. An observation that can be made from Figure $4 \mathrm{C}$ and $4 \mathrm{~F}$ is that the absolute amplitude for the semantic bias is higher in the condition where the visual competitor is absent than 
Preview
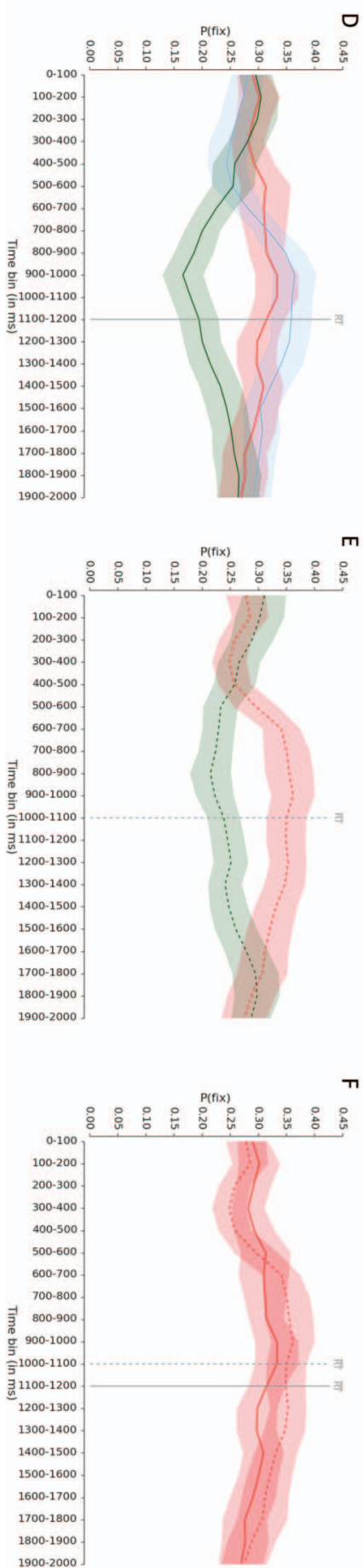

No preview

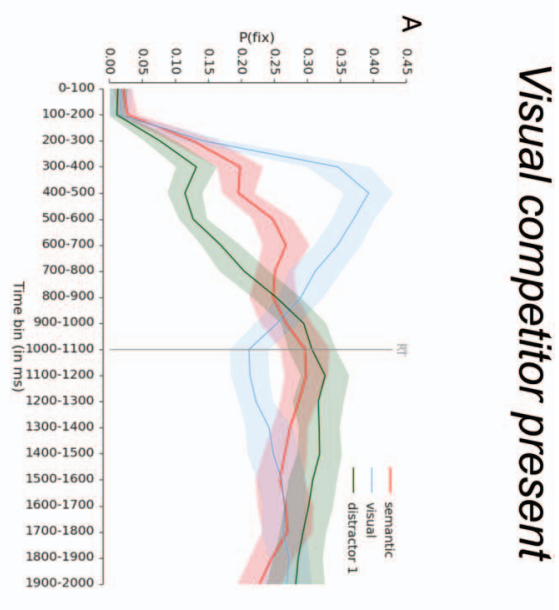

ద
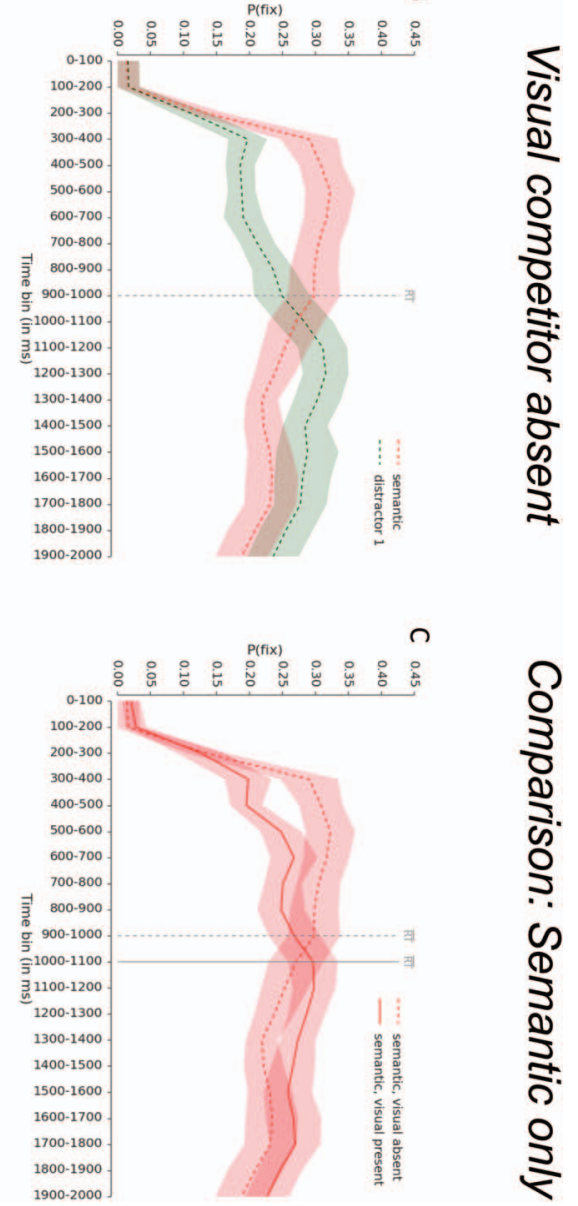

Figure 4. Fixation proportions for the different types of competitor for each $100 \mathrm{~ms}$ time bin (A, B, D, \& E) for the no preview and preview conditions in Experiment 2. The grey vertical line is placed at the time bin that includes the average reaction time. For comparison, $\mathrm{C}$ and $\mathrm{F}$ depict the time course of the semantic competitors only, for visual competitor present and absent conditions (respectively, solid and dashed lines). Confidence intervals (95\%, two-tailed) for within-participant designs (Cousineau, 2005; Morey, 2008) are plotted as error bands. See the online article for the color version of this figure. 


\section{No preview}

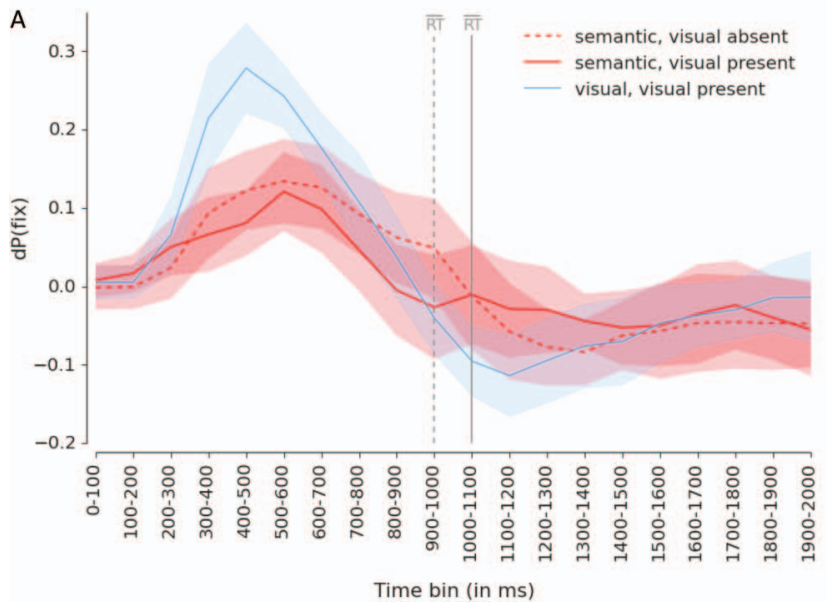

Preview

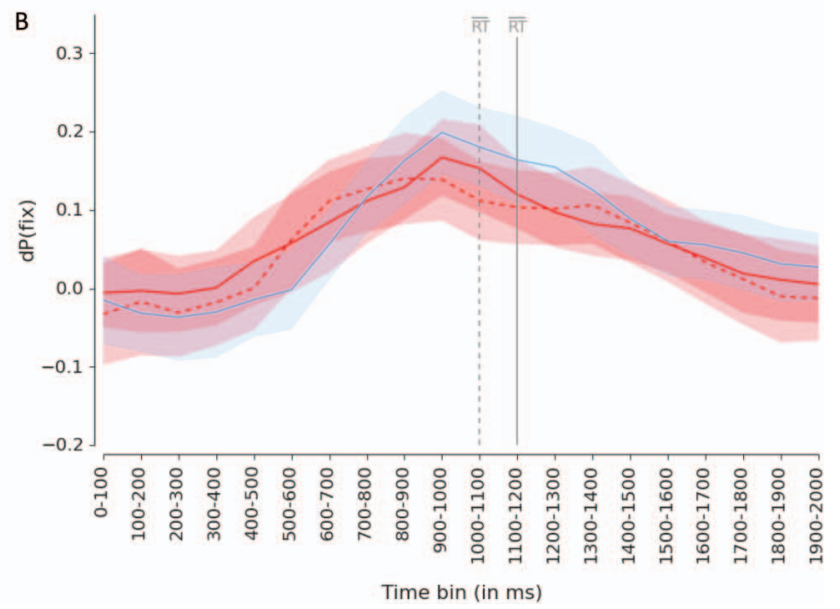

Figure 5. The difference in fixation proportion between each competitor and neutral distractor 1 in Experiment 2 , as a function of time for the no preview condition (A) and the preview condition (B). Visual competitor present and absent conditions are depicted as solid and dashed lines, respectively. The grey vertical line is placed in the time bin that includes the average reaction time. Confidence intervals (95\%, two-tailed) for within-participant designs (Cousineau, 2005; Morey, 2008) are plotted as error bands. See the online article for the color version of this figure.

in the condition where it is present. However, the same goes for the neutral distractors. This makes sense as the visual competitor takes fixations away from the other objects in the display. When baseline corrected (i.e., subtracting the fixations to the neutral distractor, see Figure 5) there is no difference in amplitude for trials with or without a visual competitor.

From Figure 5 we can also derive the temporal dynamics of the biases. In the no preview condition (Figure 5A) where the visual competitor was absent, the semantic bias started around 300 to 400 ms, peaked between 400 and $800 \mathrm{~ms}$ and was not reliable anymore from bin 900 to 1,000 ms onward. In the same condition, but now with the visual competitor present, the time course was very similar. The semantic bias arose if anything a little earlier, around 200 to $300 \mathrm{~ms}$, peaked around 400 to $700 \mathrm{~ms}$, and was no longer reliable from bin 800 to $900 \mathrm{~ms}$ onward. The visual competitor in this condition started around 200 to $300 \mathrm{~ms}$, peaked between 300 and $600 \mathrm{~ms}$, and was not reliable anymore from bin 800 to $900 \mathrm{~ms}$. The earliest difference between the semantic and the visual bias arose around bin 300 to $400 \mathrm{~ms}$. Figure 5B shows that in the preview condition, when the visual competitor was absent, the semantic bias started to differ from the neutral distractor around bin 500 to $600 \mathrm{~ms}$, peaked between 700 and 1,000 ms and was no longer reliable at bin 1,600 to $1,700 \mathrm{~ms}$. In the same condition, but now with the visual competitor present the time course was again very similar, as the semantic bias also arose around bin 500 to 600 ms, peaked between 800 and 1,100 ms and was no longer reliable at bin 1,600 to $1,700 \mathrm{~ms}$. The visual bias arose around bin 600 to $700 \mathrm{~ms}$, peaked between 800 and $1,100 \mathrm{~ms}$ and was no longer reliable at bin 1,700 to $1,800 \mathrm{~ms}$. The semantic and visual bias did not reliably differ from each other in this condition.

To determine $t_{\text {peak }}$ and peak amplitude, we applied the same cubic spline interpolation method as in Experiment 1. Table 4 shows the estimates of $t_{\text {peak }}$ and peak amplitude. To see if the results replicate those of Experiment 1, we only took the conditions in which both competitor types (visual and semantic) were present and tested whether the dynamics followed the same pattern. A repeated-measures ANOVA with condition (no preview vs. preview) and competitor type (semantic vs. visual competitor) as factors showed again a reliable interaction, $F(1,23)=15.18, p<$ $.01, \eta_{\mathrm{p}}^{2}=0.398$. Follow-up paired $t$ tests indicated that in the no preview condition the visual competitor peaked earlier than the semantic competitor, $t(23)=2.78, p<.05, r=.502$, while in the preview condition, if anything, the semantic competitor peaked earlier than the visual competitor, $t(23)=2.07, p=.05$. The same analysis was done for amplitude. Here too there was a significant interaction of condition and competitor type, $F(1,23)=19.22$, $p<.001, \eta_{\mathrm{p}}^{2}=0.455$. Follow-up paired $t$ tests revealed that in the no preview condition, the visual bias exceeded the semantic bias, $t(23)=6.21, p<.001, r=.791$. However there was no significant difference in the preview condition, $t(23)=0.19, p=.855$. As in Experiment 1, this data also suggest that the visual and semantic bias become more similar when visual stimuli are being previewed.

To assess if the presence of a visual competitor affected the temporal dynamics of the semantic bias, we analyzed $t_{\text {peak }}$ and peak amplitude for the semantic bias with a repeated-measures ANOVA with condition (no preview vs. preview) and presence of a visual competitor (present vs. absent) as factors. For $t_{\text {peak }}$ there was a main effect for condition, $F(1,23)=17.77, p<.001$, $\eta_{p}^{2}=$ 0.436 , as the semantic biases arose earlier in the no preview than in the preview condition, respectively, $632 \mathrm{~ms}(S D=240)$ and 814 $\mathrm{ms}(S D=270)$, but no main effect of presence of the visual competitor, $F(1,23)=0.38, p=.542$, nor a significant interaction, $F(1,23)=1.77, p=.196$. For amplitude, the same analysis 
showed a trend toward significance for the main effect of condition, $F(1,23)=3.37, p=.08$, if anything the bias was higher in the preview $(M=0.26, S D=0.12)$ than in the no preview condition $(M=0.22, S D=0.09)$. More important to note, there was no reliable effect of the presence of a visual competitor, $F(1$, 23) $=0.34, p=.568$, nor an interaction, $F(1,23)=1.19, p=$ .287. Additional paired $t$ tests showed that in the no preview condition, $t_{\text {peak }}$ was still earlier for the visual competitor than for the semantic competitor when the visual competitor was absent, $t(23)=2.78, p<.05, r=.502$. This was not significant in the preview condition, $t(23)=1.17, p=.255$, as there, like in Experiment 1, the dynamics of the visual bias become more similar to the dynamics of the semantic bias. Taken together, these results confirm what can also be observed from Figure 5, namely, that the presence of a visual competitor neither influences the timing nor the amplitude of the peak of the semantic bias.

Eye-movement data, target present trials. For completeness, Figure 3B shows the biases toward the target on-target present trials. In the no preview condition there is a clear deviation between the bias toward the target and the average of the nontargets from bin 200 to $300 \mathrm{~ms}$ after picture onset, whereas in the preview condition this started around 300 to $400 \mathrm{~ms}$ after word onset. In the no preview condition the bias peaked around 500 to $800 \mathrm{~ms}$, whereas in the preview condition target fixations peaked between 800 and 1,300 ms. In both conditions the biases continued after the response.

\section{General Discussion}

This study is the first to directly compare semantic and visual biases in visual search and to reveal their full time course. We report three main findings:

1. A substantial bias in orienting toward semantically related objects occurs in visual search, but this bias emerges later than biases toward visually matching objects.

2. The delay in the semantic bias can be completely undone by presenting the visual information first, before the target instruction. Thus, what is salient, visual, or semantic is not something static, but a product of the time at which the relevant cognitive processes evolve and the timing of the stimuli.

3. Although the presence of a visual competitor affects the absolute number of fixations that can go to other objects (including the semantic match), the temporal dynamics of the relative semantic bias are insensitive to the presence of visual competition and thus appear to evolve independently of any visual bias.

These findings have a number of important theoretical implications. First, theories of visual attention and, in particular, theories of visual search have largely assumed that orienting occurs on the basis of templates specifying visual features of the target objectpossibly augmented with some conceptual knowledge about where (rather than what) an object is likely to be (as in real world scene perception; see e.g., Henderson \& Ferreira, 2004). The present work provides further support for the idea that the search template not only involves the activation of visual information but also involves the activation of conceptual information about objects (Lupyan, 2008; Moores et al., 2003; Meyer et al., 2007; Telling et al., 2010). Moreover, as more detailed analyses showed, semantic similarity attracts the eyes as much as it holds them, indicating that semantic information causes attention to be captured and prevents it from being rapidly disengaged. Thus, models of visual attention will need to incorporate information on what individual objects are, not only what they look like.

Second, the results provide further evidence in support of a cascaded activation model of visual-linguistic interactions, by showing that whether orienting occurs on the basis of visual or semantic information depends on when these types of information become available in the cognitive stream of activation (Huettig \& McQueen, 2007; Huettig, Olivers, et al., 2011). Specifically, we propose that under visual search conditions, there is sufficient time for the cognitive system to preactivate both visual and semantic representations associated with the target instruction because the observer receives linguistic input as to which target to look for before the search display appears. The same is not true for the visual input: When the search display appears, the first activated representations associated with the pictures will be visual in nature, reflecting the objects' shapes and colors, before conceptual knowledge is activated. As a result, early eye movements are primarily driven by a visual match, while later eye movements will be affected by conceptual matches. The situation is however quite different under conditions of previewing the visual display (as in visual world paradigms). There the visual objects are viewed before the linguistic input, creating sufficient time for activation of both the visual and semantic representations, now associated with the pictures. When the spoken target instruction comes in, there is then opportunity for a match at both levels of representation. Our data suggest that the spoken word activates visual and semantic representations around the same time (cf. Huettig \& McQueen, 2007), with if anything a slight (but statistically not very strong) head start for semantic representations. This has wider implications for models of visual attention because so far these models have relied on a single and rather static representation of what needs to be prioritized in search - the so-called priority or saliency map. Our current data shows that what is prioritized (i.e., in this case visual vs. semantic) changes over time, suggesting a dynamically evolving saliency map (see Van Zoest, Donk, \& Theeuwes, 2004, for a similar point in a different context).

Third, the temporal dynamics of the relative semantic bias stays the same with or without visual competition. This suggests that visual and semantic representations of objects are activated independently of one other, in the sense that such representations do not seem to compete for limited cognitive resources, nor does the activation of one type of representation suppress the activation of the other. Instead, both types of influence converge at the motor level, as they are expressed in eye fixations: The presence of a visually related object took fixations away from all other objects in the display resulting in differences in the absolute fixation proportions to various competitor types. This makes sense, as the eyes can only go to one location at a time. The important finding is that the relative bias toward semantic competitors follows the same time course regardless, pointing toward independent activation.

An open question that still remains is what type of memory is involved in these types of biases. Obviously, since these effects are 
driven by visual and conceptual knowledge, long-term memory must be involved. The question is whether working memory also plays a crucial role, given that information in working memory can contribute to driving visual attention (e.g., Awh \& Jonides, 2001; Downing, 2000; Olivers, Meijer, \& Theeuwes, 2006; Soto, Heinke, Humphreys, \& Blanco, 2005; Soto \& Humphreys, 2007; Soto, Hodsoll, Rotshtein, \& Humphreys, 2008). Earlier it has been argued that working memory might be responsible for binding the temporary and rather arbitrary object location information with the activated long-term knowledge about the objects at those locations (e.g., Huettig, Olivers, et al., 2011). Note that in the current experiments the visual objects remained on the screen during search, so the question is if working memory in such a task is needed at all. However it has been argued that attention and working memory share many of the same mechanisms and that attended objects automatically enter working memory (see Olivers, 2008, for a review). In the reported experiments we used either three (Experiment 2) or four (Experiment 1) visual objects, which would fit within the commonly assumed visual working-memory capacity of approximately four items (Cowan, 2001; Vogel \& Machizawa, 2004). We also need to assume then that the objects are encoded as bound objects, with both visual and semantic properties integrated into a single representation. If visual and semantic properties were represented separately, each occupying a slot in working memory, then the number of to-be-remembered units would well exceed standard capacity. Although there is evidence for such integrated representations when purely visual features are concerned (such as color and orientation, Luck \& Vogel, 1997; Vogel, Woodman, \& Luck, 2001), direct evidence for the integration of visual and semantic information in working memory remains to be found. If anything, our timing results suggest that visual and semantic representations become active rather independently. Future studies aiming at directly investigating the role of working memory are therefore needed.

Note that despite considerable semantic biases, the bias toward visually related objects was still overall stronger. One reason for this may be that the visual similarity was simply stronger than the semantic similarity. However, our independent rating studies do not provide any evidence for this. Although it will always be difficult to compare similarity across different domains, if anything, raters indicated the semantic relationships to be stronger than the visual relationships (see Table 1). Perhaps a more plausible explanation is that the task is highly visual in nature. Observers are after all asked to look for a particular object, which might encourage participants toward using a more visual representation to guide their search. The stronger visual bias may also be because of our main dependent measure, namely eye position. Because of the strong retinotopic and spatiotopic organization of visual information, the representation of the shape and color of an object may have more direct connections to the object's location than the representation of meaning would have. Because the eye movement response we measure is also visuospatial in nature, visual matches may be relatively more influential even when both visual and semantic representations are active. Another possibility is that the semantics of objects cannot be processed extrafoveally, as has been argued by some authors (e.g., Henderson, Weeks, \& Hollingworth, 1999; Võ \& Henderson, 2011), whereas visual properties such as shapes and colors (to some extent) can. This would also explain stronger visual than semantic biases. However, in our experiments semantic competitors not only retained the eyes when people fixated them but also attracted more eye movements from elsewhere. This must mean that some of the semantics associated with objects was picked up extrafoveally, at least in the visual search condition without a preview (in the preview condition observers might have foveated the object before the word was presented). Future studies will need to address how semantic biases may be further molded by different task sets.

In sum, our results provide a case in point that one should be careful in making conclusions on which processes do or do not affect visual orienting without also taking the potential temporal dynamics of such processes into account. We have shown that the question as to whether or to what extent visual orienting is driven by semantic content is better rephrased as to when visual orienting is driven by semantic content. In semantically rich everyday scenes, objects are typically available for extended periods of time and thus so are their semantic representations. What we have shown here is that, when taking the temporal dynamics into account, it becomes obvious that semantic similarity plays a substantial role in visual selection, even in a simple laboratory search through a number of individual objects.

\section{References}

Awh, E., \& Jonides, J. (2001). Overlapping mechanisms of attention and spatial working memory. Trends in Cognitive Sciences, 5, 119-126. http://dx.doi.org/10.1016/S1364-6613(00)01593-X

Cousineau, D. (2005). Confidence intervals in within-subject designs: A simpler solution to Loftus and Masson's method. Tutorials in Quantitative Methods for Psychology, 1, 42-45.

Cowan, N. (2001). The magical number 4 in short-term memory: A reconsideration of mental storage capacity. Behavioral and Brain Sciences, 24, 87-114.

de Groot, F., Koelewijn, T., Huettig, F., \& Olivers, C. N. L. (2014). A stimulus set of words and pictures matched for visual and semantic similarity. Manuscript submitted for publication.

Donderi, D. C., \& McFadden, S. (2005). Compressed file length predicts search time and errors on visual displays. Displays, 26, 71-78. http://dx .doi.org/10.1016/j.displa.2005.02.002

Downing, P. E. (2000). Interactions between visual working memory and selective attention. Psychological Science, 11, 467-473. http://dx.doi .org/10.1111/1467-9280.00290

Duncan, J. (1983). Category effects in visual search: A failure to replicate the "oh-zero" phenomenon. Perception \& Psychophysics, 34, 221-232. http://dx.doi.org/10.3758/BF03202949

Henderson, J. M., \& Ferreira, F. (2004). Scene perception for psycholinguists. In J. M. Henderson \& F. Ferreira (Eds.), The interface of language, vision, and action: Eye movements and the visual world (pp. 1-58). New York, NY: Psychology Press.

Henderson, J. M., Weeks, P. A., Jr., \& Hollingworth, A. (1999). The effects of semantic consistency on eye movements during complex scene viewing. Journal of Experimental Psychology: Human Perception and Performance, 25, 210-228. http://dx.doi.org/10.1037/0096-1523.25.1.210

Huettig, F., \& McQueen, J. M. (2007). The tug of war between phonological, semantic and shape information in language-mediated visual search. Journal of Memory and Language, 57, 460-482. http://dx.doi .org/10.1016/j.jml.2007.02.001

Huettig, F., Olivers, C. N., \& Hartsuiker, R. J. (2011). Looking, language, and memory: Bridging research from the visual world and visual search paradigms. Acta Psychologica, 137, 138-150. http://dx.doi.org/10.1016/ j.actpsy.2010.07.013

Huettig, F., Rommers, J., \& Meyer, A. S. (2011). Using the visual world paradigm to study language processing: A review and critical evaluation. 
Acta Psychologica, 137, 151-171. http://dx.doi.org/10.1016/j.actpsy 2010.11 .003

Hwang, A. D., Wang, H. C., \& Pomplun, M. (2011). Semantic guidance of eye movements in real-world scenes. Vision Research, 51, 1192-1205. http://dx.doi.org/10.1016/j.visres.2011.03.010

Itti, L., \& Koch, C. (2001). Computational modelling of visual attention. Nature Reviews Neuroscience, 2, 194-203. http://dx.doi.org/10.1038/ 35058500

Jonides, J., \& Gleitman, H. (1972). A conceptual category effect in visual search: $\mathrm{O}$ as letter or as digit. Perception \& Psychophysics, 12, 457-460. http://dx.doi.org/10.3758/BF03210934

Keuleers, E., Brysbaert, M., \& New, B. (2010). SUBTLEX-NL: A new measure for Dutch word frequency based on film subtitles. Behavior Research Methods, 42, 643-650. http://dx.doi.org/10.3758/BRM.42.3 .643

Luck, S. J., \& Vogel, E. K. (1997). The capacity of visual working memory for features and conjunctions. Nature, 390, 279-281. http://dx.doi.org/ $10.1038 / 36846$

Lupyan, G. (2008). The conceptual grouping effect: Categories matter (and named categories matter more). Cognition, 108, 566-577. http://dx.doi .org/10.1016/j.cognition.2008.03.009

Mathôt, S., Schreij, D., \& Theeuwes, J. (2012). OpenSesame: An opensource, graphical experiment builder for the social sciences. Behavior Research Methods, 44, 314-324. http://dx.doi.org/10.3758/s13428-0110168-7

Meyer, A. S., Belke, E., Telling, A. L., \& Humphreys, G. W. (2007). Early activation of object names in visual search. Psychonomic Bulletin \& Review, 14, 710-716. http://dx.doi.org/10.3758/BF03196826

Moores, E., Laiti, L., \& Chelazzi, L. (2003). Associative knowledge controls deployment of visual selective attention. Nature Neuroscience, 6, 182-189. http://dx.doi.org/10.1038/nn996

Morey, R. D. (2008). Confidence intervals from normalized data: A correction to Cousineau (2005). reason, 4, 61-64.

Olivers, C. N. (2008). Interactions between visual working memory and visual attention. Frontiers in Bioscience, 13, 1182-1191. http://dx.doi .org/10.2741/2754

Olivers, C. N., Meijer, F., \& Theeuwes, J. (2006). Feature-based memorydriven attentional capture: Visual working memory content affects visual attention. Journal of Experimental Psychology: Human Perception and Performance, 32, 1243-1265. http://dx.doi.org/10.1037/0096-1523 .32.5.1243

Riesenhuber, M., \& Poggio, T. (1999). Hierarchical models of object recognition in cortex. Nature Neuroscience, 2, 1019-1025. http://dx.doi .org/10.1038/14819

Schroeder, C. E., Mehta, A. D., \& Givre, S. J. (1998). A spatiotemporal profile of visual system activation revealed by current source density analysis in the awake macaque. Cerebral Cortex, 8, 575-592. http://dx .doi.org/10.1093/cercor/8.7.575
Soto, D., Heinke, D., Humphreys, G. W., \& Blanco, M. J. (2005). Early, involuntary top-down guidance of attention from working memory. Journal of Experimental Psychology: Human Perception and Performance, 31, 248-261. http://dx.doi.org/10.1037/0096-1523.31.2.248

Soto, D., Hodsoll, J., Rotshtein, P., \& Humphreys, G. W. (2008). Automatic guidance of attention from working memory. Trends in Cognitive Sciences, 12, 342-348. http://dx.doi.org/10.1016/j.tics.2008.05.007

Soto, D., \& Humphreys, G. W. (2007). Automatic guidance of visual attention from verbal working memory. Journal of Experimental Psychology: Human Perception and Performance, 33, 730-737. http://dx .doi.org/10.1037/0096-1523.33.3.730

Telling, A. L., Kumar, S., Meyer, A. S., \& Humphreys, G. W. (2010). Electrophysiological evidence of semantic interference in visual search. Journal of Cognitive Neuroscience, 22, 2212-2225.

Theeuwes, J. (2010). Top-down and bottom-up control of visual selection. Acta Psychologica, 135, 77-99. http://dx.doi.org/10.1016/j.actpsy.2010.02 .006

van Heuven, W. J., Mandera, P., Keuleers, E., \& Brysbaert, M. (2014). SUBTLEX-UK: A new and improved word frequency database for British English. Quarterly Journal of Experimental Psychology, 67, 1176-1190. http://dx.doi.org/10.1080/17470218.2013 .850521

van Zoest, W., Donk, M., \& Theeuwes, J. (2004). The role of stimulusdriven and goal-driven control in saccadic visual selection. Journal of Experimental Psychology: Human Perception and Performance, 30, 746-759. http://dx.doi.org/10.1037/0096-1523.30.4.749

Võ, M. L., \& Henderson, J. M. (2011). Object-scene inconsistencies do not capture gaze: Evidence from the flash-preview moving-window paradigm. Attention, Perception, \& Psychophysics, 73, 1742-1753. http://dx .doi.org/10.3758/s13414-011-0150-6

Vogel, E. K., \& Machizawa, M. G. (2004). Neural activity predicts individual differences in visual working memory capacity. Nature, 428 748-751. http://dx.doi.org/10.1038/nature02447

Vogel, E. K., Woodman, G. F., \& Luck, S. J. (2001). Storage of features, conjunctions, and objects in visual working memory. Journal of Experimental Psychology: Human Perception and Performance, 27, 92-114. http://dx.doi.org/10.1037/0096-1523.27.1.92

White, M. J. (1977). Identification and categorization in visual search. Memory \& Cognition, 5, 648-657. http://dx.doi.org/10.3758/ BF03197411

Wolfe, J. M. (2007). Guided search 4.0: Current progress with a model of visual search. In W. D. Gray (Ed.), Integrated models of cognitive systems (pp. 99-119). New York, NY: Oxford University Press. http:// dx.doi.org/10.1093/acprof:oso/9780195189193.003.0008

Wolfe, J. M., \& Horowitz, T. S. (2004). What attributes guide the deployment of visual attention and how do they do it? Nature Reviews Neuroscience, 5, 495-501. http://dx.doi.org/10.1038/ nrn1411 


\section{Appendix}

\section{The 120 Target Absent Trials}

\begin{tabular}{|c|c|c|c|c|c|}
\hline Trial & Spoken word & Semantic competitor & Visual competitor & Neutral Distractor 1 & Neutral Distractor 2 \\
\hline 1 & aardappel (potato) & maïskolf (corn cob) & bowlingbal (bowling ball) & batterij (battery) & potlood (pencil) \\
\hline $2^{*}$ & antenne (antenna) & televisie (television) & sigaret (cigarette) & trampoline (trampoline) & kiwi (kiwi) \\
\hline $3^{*}$ & $\operatorname{arm}(\operatorname{arm})$ & hersenen (brain) & boemerang (boomerang) & waterscooter (jet ski) & $\begin{array}{l}\text { plakbandhouder (tape } \\
\text { including holder) }\end{array}$ \\
\hline 4 & asbak (ashtray) & pijp (pipe) & jojo (yoyo) & dennenappel (pinecone) & rozen (roses) \\
\hline 5 & bad (bath tub) & kraan (faucet) & slee (slay) & $\begin{array}{l}\text { honkbalhandschoen (baseball } \\
\text { glove) }\end{array}$ & kwast (brush) \\
\hline 6 & badpak (bathing suit) & slippers (flip flops) & kruik (hot water bottle) & nietjes (staples) & $\begin{array}{l}\text { koffiezetapparaat (coffee } \\
\text { maker) }\end{array}$ \\
\hline 7 & bakblik (oven tin) & taart (pie) & $\begin{array}{l}\text { cassettebandje (cassette } \\
\text { tape) }\end{array}$ & schaats (ice skate) & stropdas (tie) \\
\hline 8 & bal (ball) & $\begin{array}{l}\text { voetbalschoenen (soccer } \\
\text { cleats) }\end{array}$ & tomaat (tomato) & waterpijp (hookah) & schep (shovel) \\
\hline 9 & ballon (balloon) & cadeau (present) & kers (cherry) & kaasschaaf (cheese slicer) & koffiebonen (coffee beans) \\
\hline 10 & banaan (banana) & aap (monkey) & kano (canoe) & tamboerijn (tambourine) & hoed (hat) \\
\hline 11 & basketbal (basketball) & $\begin{array}{l}\text { badmintonracket (badminton } \\
\text { racket) }\end{array}$ & kokosnoot (coconut) & steekwagen (handtruck) & stanleymes (box cutter) \\
\hline 12 & beker (mug) & vork (fork) & garen (thread) & pen (pen) & duikbril (goggles) \\
\hline 13 & blokken (blocks) & hobbelpaard (rocking horse) & toffee (toffee) & saxofoon (saxophone) & beer (bear) \\
\hline 14 & bolhoed (bowler hat) & wandelstok (walking stick) & citruspers (juicer) & vlees (meat) & olifant (elephant) \\
\hline 15 & boom (tree) & bijl (axe) & wc-borstel (toilet brush) & magnetron (microwave) & magneet (magnet) \\
\hline 16 & boor (drill) & rolmaat (measuring tape) & pistool (hand gun) & ballon (balloon) & bureaustoel (office chair) \\
\hline 17 & boot (boat) & anker (anchor) & klomp (clog) & chocolade (chocolate) & honkbal (baseball) \\
\hline 18 & bot (bone) & puppy (puppy) & halter (dumb-bell) & bezem (broom) & narcis (narcissus) \\
\hline $19^{*}$ & brievenbus (mailbox) & postzegels (stamps) & broodrooster (toaster) & ijslepel (ice cream scooper) & fluit (recorder) \\
\hline 20 & bril (glasses) & telescoop (telescope) & bh (bra) & scheermes (razor) & sleutel (key) \\
\hline 21 & buggy (buggy) & flesje (baby bottle) & tractor (tractor) & sneeuwschuiver (snow shovel) & zonnebloem (sunflower) \\
\hline 22 & $\mathrm{~cd}(\mathrm{~cd})$ & diskette (floppy disk) & reddingsboei (life saver) & holster (holster) & duimstok (yard stick) \\
\hline 23 & drol (turd) & luier (diaper) & ijsje (ice cream cone) & kan (jar) & pompoen (pumpkin) \\
\hline 24 & druiven (grapes) & wijnglas (wine glass) & $\begin{array}{l}\text { biljartballen (billiard } \\
\text { balls) }\end{array}$ & kettingzaag (chainsaw) & bel (bell) \\
\hline 25 & drumstel (drum kit) & $\begin{array}{l}\text { elektrischegitaar (electric } \\
\text { guitar) }\end{array}$ & weegschaal (scale) & katapult (sling shot) & $\begin{array}{l}\text { speelkaarten (playing } \\
\text { cards) }\end{array}$ \\
\hline 26 & ei $(\mathrm{egg})$ & haan (rooster) & wol (yarn) & tandenborstel (toothbrush) & xylofoon (xylophone) \\
\hline 27 & fles (bottle) & kurk (cork) & kegel (pin) & broek (pants) & kerstbal (bauble) \\
\hline 28 & fluit (recorder) & harp (harp) & deegroller (rolling pin) & badeend (rubber duck) & ton (barrel) \\
\hline 29 & garde (whisk) & schaal (bowl) & borstel (hair brush) & speldenkussen (pincushion) & pillen (pills) \\
\hline 30 & gloeilamp (light bulb) & lichtschakelaar (light switch) & avocado (avocado) & adelaar (eagle) & mand (basket) \\
\hline 31 & $\begin{array}{l}\text { handboeien } \\
\text { (handcuffs) }\end{array}$ & politiepet (police hat) & trappers (pedals) & scheerkwast (shaving brush) & hijskraan (crane) \\
\hline 32 & handboog (longbow) & kanon (cannon) & ijzerzaag (hacksaw) & ananas (pineapple) & nagellak (nail polish) \\
\hline $33^{*}$ & handdoek (towel) & bad (bath tub) & zonnescherm (sunshade) & monitor (monitor) & vogelhuisje (birdhouse) \\
\hline 34 & hark (rake) & $\begin{array}{l}\text { heggenschaar (hedge } \\
\text { trimmer) }\end{array}$ & spatel (spatula) & dynamiet (dynamite) & zwemband (inner tube) \\
\hline 35 & helm (helmet) & motor (engine) & mango (mango) & blik (dustpan) & ijshoorntje (cone) \\
\hline $36^{*}$ & hersenen (brains) & neus (nose) & bloemkool (cauliflower) & koekje (cookie) & nijptang (pincers) \\
\hline 37 & hijskraan (crane) & cementwagen (cement truck) & giraf (giraffe) & kopje (cup) & bramen (blackberries) \\
\hline 38 & hoefijzer (horseshoe) & zadel (saddle) & koptelefoon (headphones) & teddybeer (teddy bear) & brie (brie) \\
\hline 39 & ipod (iPod) & radio (radio) & kompas (compass) & watermeloen (watermelon) & flesopener (bottle opener) \\
\hline $40^{*}$ & jas (coat) & want (mitten) & tuitbeker (sippy cup) & platenspeler (turntable) & snoepjes (candy) \\
\hline 41 & jerrycan (jerry can) & benzinepomp (petrol pump) & paprika (bell pepper) & ventilator (fan) & telefoon (phone) \\
\hline $42^{*}$ & joystick (joystick) & toetsenbord (keyboard) & tol (top $[$ toy]) & klamboe (mosquito net) & kuiken (chick) \\
\hline 43 & $\begin{array}{l}\text { kleerhanger (clothes } \\
\text { hanger) }\end{array}$ & kapstok (coat hanger) & triangel (triangle) & $\begin{array}{l}\text { luidspreker (megaphone } \\
\text { loudspeaker) }\end{array}$ & driewieler (tricycle) \\
\hline 44 & klokhuis (apple core) & aardbei (strawberry) & vaas (vase) & portemonnee (wallet) & hamer (hammer) \\
\hline 45 & koekje (cookie) & chips (potato chips) & pleister (Band-Aid) & boog (bow) & $\begin{array}{l}\text { thermometer } \\
\text { (thermometer) }\end{array}$ \\
\hline 46 & Koelkast (refrigerator) & ijskristal (snow flake) & mobiel toilet (porta-potty) & skeeler (roller blade) & naald (needle) \\
\hline
\end{tabular}


Appendix (continued)

\begin{tabular}{|c|c|c|c|c|c|}
\hline Trial & Spoken word & Semantic competitor & Visual competitor & Neutral Distractor 1 & Neutral Distractor 2 \\
\hline 47 & koffer (suitcase) & trein (train) & lantaarn (lantern) & stoel (chair) & olijf (olive) \\
\hline 48 & krijtjes (chalks) & palet (palette) & spelden (pins) & kikker (frog) & trommel (drum) \\
\hline 49 & krokodil (crocodile) & uil (owl) & augurk (pickle) & $\begin{array}{l}\text { bokshandschoenen (boxing } \\
\text { gloves) }\end{array}$ & tandartsstoel (dental chair) \\
\hline 50 & kussen (pillow) & $\begin{array}{l}\text { schommelstoel (rocking } \\
\text { chair) }\end{array}$ & ravioli (ravioli) & leeuw (lion) & asbak (ashtray) \\
\hline 51 & lampion (lampion) & zaklamp (flashlight) & bandoneon (accordion) & peultje (sugar snap) & hagedis (lizard) \\
\hline 52 & lasso (lasso) & cowboyhoed (cowboy hat) & waterslang (water hose) & stemvork (tuning fork) & tas (bag) \\
\hline 53 & liniaal (ruler) & perforator (hole puncher) & $\operatorname{kam}(\mathrm{comb})$ & pannenkoeken (pancakes) & drinkzak (camel bag) \\
\hline 54 & lippenstift (lipstick) & parfum (perfume) & aansteker (lighter) & cruiseschip (cruise ship) & zak (paper bag) \\
\hline 55 & loep (lens) & microscoop (microscope) & $\begin{array}{l}\text { tafeltennisbatje (ping } \\
\text { pong paddle) }\end{array}$ & prullenbak (trash can) & reddingsvest (life vest) \\
\hline 56 & medaille (medal) & trofee (trophy) & bord (plate) & garnaal (shrimp) & $\begin{array}{c}\text { schroevendraaier } \\
\text { (screwdriver) }\end{array}$ \\
\hline 57 & meloen (melon) & bananen (bananas) & rugbybal (rugby ball) & golfclub (golf club) & raket (rocket) \\
\hline 58 & mes (knife) & theepot (teapot) & peddel (paddle) & poederdoos (face powder box) & babybedje (play crib) \\
\hline 59 & $\begin{array}{l}\text { microfoon } \\
\quad \text { (microphone) }\end{array}$ & boxjes (speakers) & pizzasnijder (pizza cutter) & ketel (kettle) & $\begin{array}{l}\text { vuilniszakken (garbage } \\
\text { bags) }\end{array}$ \\
\hline $60^{*}$ & mijter (miter) & staf (staff) & pylon (pylon) & bergschoen (mountain boot) & fax (fax machine) \\
\hline 61 & $\begin{array}{l}\text { milkshake (milk } \\
\text { shake) }\end{array}$ & friet (french fries) & $\begin{array}{l}\text { walkietalkie (Walkie- } \\
\text { Talkie) }\end{array}$ & wetsuit (wet suit) & $\begin{array}{l}\text { snelheidsmeter } \\
\text { (speedometer) }\end{array}$ \\
\hline 62 & monitor (monitor) & muis (mouse) & dienblad (tray) & notenkraker (nutcracker) & rietjes (straws) \\
\hline 63 & naald (needle) & vingerhoedje (thimble) & dwarsfluit (flute) & fiets (bicycle) & boek (book) \\
\hline 64 & oog (eye) & haar (wig) & globe (globe) & broccoli (broccoli) & politieauto (police car) \\
\hline 65 & oor (ear) & voet (foot) & croissant (croissant) & schildersezel (easel) & vrachtwagen (truck) \\
\hline 66 & oven (oven) & koekenpan (frying pan) & kastje (cabinet) & honkbalknuppel (baseball bat) & tijger (tiger) \\
\hline 67 & pannenkoek (pancake) & brood (bread) & klok (clock) & ketting (chain) & vijl (nail file) \\
\hline 68 & paraplu (umbrella) & regenlaarzen (rain boots) & krukje (stool) & $\begin{array}{l}\text { veiligheidsspelden (safety } \\
\text { pins) }\end{array}$ & kruiwagen (wheelbarrow) \\
\hline 69 & piano (piano) & trompet (trumpet) & barcode (barcode) & riem (belt) & bureaulamp (desk light) \\
\hline 70 & pinguïn (penguin) & ijsbeer (polar bear) & champagne (champagne) & tissues (tissues) & bureau (desk) \\
\hline 71 & pinpas (debit card) & euro (euro) & envelop (envelope) & blad (leaf) & zwaan (swan) \\
\hline 72 & plakband (scotch tape) & paperclip (paper clip) & toiletpapier (toilet paper) & pijl (arrow) & zonnebril (sunglasses) \\
\hline 73 & plant (plant) & gieter (watering can) & feesttoeter (party horn) & nagelknipper (nail clipper) & controller (controller) \\
\hline $74^{*}$ & portemonnee (wallet) & geld (money) & kussen (pillow) & zebra (zebra) & gong (gong) \\
\hline 75 & potlood (pencil) & $\begin{array}{l}\text { puntenslijper (pencil } \\
\text { sharpener) }\end{array}$ & schroef (screw) & skelet (skeleton) & kat (cat) \\
\hline $76^{*}$ & raam (window) & schoorsteen (chimney) & schilderij (painting) & vishaak (lure) & zalmmoot (salmon fillet) \\
\hline 77 & radiator (radiator) & kachel (heater) & dranghek (fence) & boon (bean) & nietmachine (stapler) \\
\hline 78 & raket (rocket) & $\operatorname{tank}(\operatorname{tank})$ & vuurtoren (lighthouse) & toilettas (toiletry bag) & dalmatiër (dalmatian) \\
\hline $79^{*}$ & rasp (grater) & kaas (cheese) & $\begin{array}{r}\text { wolkenkrabber } \\
\text { (skyscraper) }\end{array}$ & backpack (backpack) & $\begin{array}{l}\text { brandweerhelm (fireman's } \\
\text { helmet) }\end{array}$ \\
\hline 80 & rat (rat) & muizenval (mousetrap) & $\begin{array}{l}\text { stekkerdoos (extension } \\
\text { cord) }\end{array}$ & horloge (watch) & brug (bridge) \\
\hline 81 & riem (belt) & sokken (socks) & slang (snake) & dartbord (dartboard) & cappuccino (cappuccino) \\
\hline 82 & ring (ring) & oorbellen (earrings) & donut (donut) & telraam (abacus) & prei (leek) \\
\hline 83 & rog (stingray) & zeepaardje (sea horse) & vliegtuig (plane) & bierflesje (beer bottle) & discobal (disco ball) \\
\hline $84^{*}$ & $\begin{array}{l}\text { schaakbord } \\
\text { (chessboard) }\end{array}$ & dobbelstenen (dice) & theedoek (dishcloth) & mixer (mixer) & bloempot (flower pot) \\
\hline $85^{*}$ & scheermes (razor) & zeeppompje (soap dispenser) & fietspomp (bicycle pump) & piramide (pyramid) & tram (tram) \\
\hline 86 & schildpad (tortoise) & viskom (fishbowl) & noot (nut) & vaatwasser (dishwasher) & $\begin{array}{l}\text { winkelwagen (shopping } \\
\text { cart) }\end{array}$ \\
\hline 87 & schoen (shoe) & pet (baseball cap) & strijkijzer (iron) & propeller (propeller) & pakket (packet) \\
\hline $88^{*}$ & schoorsteen (chimney) & dak (roof) & trechter (funnel) & $\begin{array}{l}\text { dubbeldekker (double decker } \\
\text { bus) }\end{array}$ & peer (pear) \\
\hline 89 & $\begin{array}{l}\text { shuttle (badminton } \\
\text { birdie) }\end{array}$ & tennisbal (tennis-ball) & gloeilamp (light bulb) & pasta (pasta) & dunschiller (potato peeler) \\
\hline 90 & sinaasappel (orange) & courgette (zucchini) & golfbal (golf ball) & kalf (calf) & snijplank (cutting board) \\
\hline 91 & ski’s (skis) & muts (beanies) & pincet (tweezers) & ezel (donkey) & peper (pepper) \\
\hline
\end{tabular}


Appendix (continued)

\begin{tabular}{|c|c|c|c|c|c|}
\hline Trial & Spoken word & Semantic competitor & Visual competitor & Neutral Distractor 1 & Neutral Distractor 2 \\
\hline 92 & sleutel (key) & kluis (safe) & kurkentrekker (corkscrew) & basketbal (basketball) & $\begin{array}{l}\text { spinnewiel (spinning } \\
\text { wheel) }\end{array}$ \\
\hline 93 & slof (slipper) & badjas (bathrobe) & cavia (guinea pig) & filmrol (film) & strijkplank (ironing board) \\
\hline 94 & $\begin{array}{l}\text { snijplank (cutting } \\
\text { board) }\end{array}$ & hakmes (cleaver) & laptop (laptop) & kerstkrans (christmas wreath) & jas (jacket) \\
\hline 95 & snoep (candy) & hamburger (hamburger) & knikkers (marbles) & $\begin{array}{l}\text { wasmachine (washing } \\
\text { machine) }\end{array}$ & fototoestel (camera) \\
\hline 96 & spaghetti (spaghetti) & vergiet (colander) & touw (rope) & verkeerslicht (traffic light) & klarinet (clarinet) \\
\hline 97 & speen (pacifier) & babypakje (onesies) & pion (pawn) & picknicktafel (picnic table) & dolfijn (dolphin) \\
\hline $98^{*}$ & $\begin{array}{l}\text { sperzieboon (butter } \\
\text { bean) }\end{array}$ & ui (onion) & sabel (saber) & spiegel (mirror) & douchekop (shower head) \\
\hline 99 & spook (ghost) & grafsteen (tombstone) & shuttle (badminton birdie) & hondenriem (dog leash) & $\begin{array}{l}\text { koffiemolen (coffee } \\
\text { grinder) }\end{array}$ \\
\hline 100 & spuit (injection) & stethoscoop (stethoscope) & dartpijl (dart) & dominostenen (dominoes) & fornuis (stove) \\
\hline $101^{*}$ & stift (pin) & notitieboekje (notebook) & pipet (pipette) & vliegenmepper (fly swatter) & kist (chest) \\
\hline 102 & stijgbeugel (stirrup) & paard (horse) & stamper (masher) & hotdog (hot dog) & palmboom (palm tree) \\
\hline $103^{*}$ & stopcontact (socket) & stekker (plug) & knoop (button) & sjaal (scarf) & $\begin{array}{l}\text { luchtballon (hot air } \\
\text { balloon) }\end{array}$ \\
\hline 104 & $\begin{array}{l}\text { strijkplank (ironing } \\
\text { board) }\end{array}$ & wasmand (laundry basket) & keyboard (keyboard) & bloem (flower) & hand (hand) \\
\hline $105^{*}$ & stropdas (tie) & trui (sweater) & vlieger (kite) & rolstoel (wheelchair) & Videoband (videotape) \\
\hline 106 & surfplank (surfboard) & badpak (bathing suit) & veer (feather) & bizon (bison) & graafmachine (excavator) \\
\hline 107 & sushi (sushi) & eetstokjes (chopsticks) & duct tape (duct tape) & kruisboog (crossbow) & step (scooter) \\
\hline 108 & $\begin{array}{l}\text { tamboerijn } \\
\quad(\text { tambourine })\end{array}$ & viool (violin) & pizza (pizza) & wattenstaafje (cotton swab) & kruk (stool) \\
\hline 109 & televisie (television) & $\begin{array}{l}\text { afstandsbediening (remote } \\
\text { control) }\end{array}$ & schoolbord (blackboard) & trombone (trombone) & $\begin{array}{l}\text { cowboylaarzen (cowboy } \\
\text { boots) }\end{array}$ \\
\hline $110^{*}$ & tent (tent) & gasflesje (camping burner) & geodriehoek (protractor) & neushoorn (rhino) & brandweerauto (fire truck) \\
\hline 111 & theepot (teapot) & lepel (spoon) & kandelaar (candle holder) & sportschoenen (sneakers) & bretels (suspenders) \\
\hline 112 & toffee (toffee) & gebit (teeth) & vlinderdas (bow tie) & agenda (agenda) & hout (wood) \\
\hline 113 & trappers (pedals) & wiel (wheel) & verfroller (paint roller) & haai (shark) & glijbaan (slide) \\
\hline 114 & visnet (fishnet) & kreeft (lobster) & zeef (sieve) & lantaarnpaal (lamp post) & $\begin{array}{l}\text { scheerapparaat (electric } \\
\text { razor) }\end{array}$ \\
\hline 115 & vlieger (kite) & springtouw (jump rope) & $\begin{array}{l}\text { voorrangsbord (traffic } \\
\text { sign) }\end{array}$ & geweer (rifle) & printer (printer) \\
\hline 116 & vliegtuig (airplane) & label (label) & kruis (cross) & worst (sausage) & $\begin{array}{l}\text { muffin bakvorm (muffin } \\
\text { tin) }\end{array}$ \\
\hline 117 & vlinder (butterfly) & rups (caterpillar) & $\begin{array}{l}\text { gereedschapskist (tool } \\
\text { box) }\end{array}$ & rijst (rice) & slot (lock) \\
\hline $118^{*}$ & wortel (carrot) & appel (apple) & schelp (shell) & usb-stick (usb stick) & frisbee (frisbee) \\
\hline 119 & zaklamp (flashlight) & kaars (candle) & ontstopper (plunger) & ijsblokjesvorm (ice cube tray) & flippers (flippers) \\
\hline 120 & zweep (whip) & cap (derby hat) & hengel (fishing rod) & verrekijker (binocular) & framboos (raspberry) \\
\hline
\end{tabular}

Note. The last four columns are the intended names of the pictures in Dutch (and within brackets the English translation). The trials with an asterisk are an extension of the 100 trials described in de Groot et al. (2014).

Received November 4, 2014

Revision received April 15, 2015

Accepted June 1, 2015 